\title{
Prandtl Number Effects on the Entropy Generation During the Transient Mixed Convection in a Square Cavity Heated from Below
}

\author{
Nawal Ferroudj ${ }^{1,2 *}$, Hasan Koten ${ }^{3}$, Sacia Kachi', Saadoun Boudebous ${ }^{4}$ \\ ${ }^{1}$ Chemical Engineering Department, Faculty of Process Engineering, University of Salah Boubnider Constantine 3, \\ 25000 Constantine, P.O.B. 'B' 72, Algeria \\ 2 Laboratory of Biotechnology, National Higher School of Biotechnology (ENSB), University town Ali Mendjeli, Constantine 3, \\ 25100 Constantine, P.O.B. E66, Algeria \\ ${ }^{3}$ Computational Fluid Dynamics Laboratory, Department of Mechanical Engineering, Istanbul Medeniyet University, 34700 \\ Istanbul, Goztep Campus, E5 Street, Turkey \\ ${ }^{4}$ Faculty of Sciences and Applied Sciences, University of Larbi Ben M'hidi, 04000 Oum el Bouaghi, P.O.B. 358, Algeria \\ * Corresponding author, e-mail: n.ferroudj@ensbiotech.edu.dz
}

Received: 21 November 2020, Accepted: 07 May 2021, Published online: 30 August 2021

\begin{abstract}
This numerical study considers the mixed convection, heat transfer and the entropy generation within a square cavity partially heated from below with moving cooled vertical sidewalls. All the other horizontal sides of the cavity are assumed adiabatic. The governing equations, in stream function-vorticity form, are discretized and solved using the finite difference method. Numerical simulations are carried out, by varying the Richardson number, to show the impact of the Prandtl number on the thermal, flow fields, and more particularly on the entropy generation. Three working fluid, generally used in practice, namely mercury $(\operatorname{Pr}=0.0251)$, air $(\operatorname{Pr}=0.7296)$ and water $(\mathrm{Pr}=6.263)$ are investigated and compared. Predicted streamlines, isotherms, entropy generation, as well as average Nusselt numbers are presented. The obtained results reveal that the impact of the Prandtl number is relatively significant both on the heat transfer performance and on the entropy generation. The average Nusselt number increase with increasing Prandtl number. Its value varies thereabouts from 3.7 to 3.8 for mercury, from 5.5 to 13 for air and, from 12.5 to 15 for water. In addition, it is found that the total average entropy generation is significantly higher in the case of mercury ( $\operatorname{Pr} \ll 1)$ and water ( $\operatorname{Pr} » 1)$ than in the case of air ( $\operatorname{Pr} \sim 1)$. Its value varies approximately from 700 to $1100 \mathrm{~W} / \mathrm{m}^{3} \mathrm{~K}$ for mercury, from 200 to $500 \mathrm{~W} / \mathrm{m}^{3} \mathrm{~K}$ for water and, from 0.03 to $5 \mathrm{~W} / \mathrm{m}^{3} \mathrm{~K}$ for air.
\end{abstract}

\section{Keywords}

Prandtl number, entropy generation, mixed convection, square cavity, finite difference method

This article was originally published with an error. This version has been corrected/amended in the Corrigendum. Please see the Corrigendum (https://doi.org/10.3311/PPme.19293)!

\section{Introduction}

Thermal resistance and friction are mechanisms that generate irreversibility during fluid flows present in any heat transfer process. However, the first and second laws of thermodynamics indicate that these irreversibilities give rise to a loss of available work in the processes of heat transfer. This loss of useful work is referred to as "entropy generation". The most important theoretical studies of entropy generation in heat transfer processes have been reported in several references works e.g. Bejan $[1,2]$. The fundamental concepts of energy, entropy and exergy and their applications in many fields of science and technology were well detailed by Dincer and Cengel [3], Naterer and Camberos [4], Sciacovelli et al. [5] and more recently by Sauerheber [6]. One of the main challenges of thermal engineering is to minimize the entropy generation of in a system to collect the maximum useful work and thus to improve the energy efficiency of the system $[7,8]$. In the literature, several studies have been reported on entropy generation of buoyancy flows in enclosures subjected to different boundary conditions. Oztop and Al-Salem [9] reported a comprehensive review of entropy generation in buoyancy-induced flows in cavities and channels. Awad [10] presented a critical review of the thermodynamic optimum of micro channels based on entropy generation analysis. More recently, Biswal and Basak [11] performed a detailed review of the literature on the entropy generation analysis for heat transfer processes involving various practical applications. In addition, it should also be pointed out that 
Torabi et al. [12] reported a concise review of a large number of studies where efforts were made to integrate entropy generation in thermal systems with solid structures including also convective-conductive problems in which the conductive process has dominating roles.

In the last decade, significant numerical investigations [13-16] have been performed to include the effect of the Prandtl number during laminar natural or mixed convection in confined spaces. However, the literature review has revealed that few contributions have been made to the effect of the Prandtl number on entropy generation, whether in natural convection or mixed convection. Firstly, as to the natural convection, Kaluri and Basak [17] performed numerical studies on entropy generation during natural convection in porous square cavities heated with differential and distributed heating. Simulations were carried out for a range of permeability of a porous medium between $10^{-6}$ and $10^{-3}$, Rayleigh numbers between $10^{3}$ and $10^{6}$ and for values of the Prandtl numbers = equal to $0.015,0.7,10,1000$. They found that friction irreversibility dominates the total entropy generation for higher Prandtl numbers at higher Darcy numbers, whereas the heat transfer irreversibility dominates the total entropy generation for lower Prandtl numbers. Ramakrishna et al. [18] studied the entropy generation for natural convection within trapezoidal cavities in the presence of a hot left wall, cold right wall, and adiabatic horizontal walls. The results were reported for Rayleigh number $(\mathrm{Ra})=10^{6}$, Prandtl numbers $(\operatorname{Pr})=0.015$ and 1000 and Darcy numbers $(\mathrm{Da})=10^{-4}$ and $10^{-5}$. One of their conclusions is that the total entropy generation is found to be high for $\operatorname{Pr}=1000$ compared to that of $\operatorname{Pr}=0.015$ at higher Da. Analysis of the variation of average Bejan number with Da illustrated that the fluid friction irreversibility contributes significantly to the increase in total entropy generation. Rathnam et al. [19] studied the influence of the Rayleigh numbers $\left(\mathrm{Ra}=10^{3}-10^{5}\right)$, the Prandtl numbers $\left(\operatorname{Pr}=1.510^{-2}-10^{3}\right)$ and the base angles $\left(\varphi=45^{\circ}\right.$ and $\left.60^{\circ}\right)$ on entropy generation during natural convection in isosceles triangular cavities for various base angles or tilt positions. They were able to determine the most suitable parameters as well as geometric configuration to minimize the entropy generation. More recently, Wei et al. [20] used the lattice Boltzmann Method in order to simulate the effect of Prandtl number on the entropy generation in Rayleigh-Bénard convection processes. The Rayleigh number was set at $5.410^{9}$ while the values of the Prandtl number were 6, 20, 100 and $10^{6}$. It was shown that the viscous entropy generation increases progressively with the increase in Prandtl number; the entropy generation in the flow is dominated by heat transfer irreversibility and frictional irreversibility can be neglected. Very recently, it has been noted, in the literature, that the presence of radiation and magnetic field in enclosures filled with various nanofluids has considerably influenced the generation of entropy on natural convection as evidenced by the work of Pordanjani et al. [21] and Mliki and Abbassi [22].

Secondly, as to the mixed convection, Roy et al. [23-25] investigated the effect of the Prandtl on entropy generation during the mixed convection in a square cavity where the bottom wall is isothermally hot, sidewalls are cold, and the top wall is adiabatic. Simulations were carried out for Prandtl number Pr $=0.026$ and 7.2, the Reynolds number Re varied between 10 and 100, and Grashof number $\mathrm{Gr}$ varied between $10^{3}$ and $10^{5}$. In Roy et al. [23] the effect of moving horizontal or vertical wall(s) was considered, in Roy et al. [24], the cavity was filled with porous media and the effect of thermal boundary condition was highlighted and in Roy et al. [25] the effect of various thermal boundary conditions is studied. More recently, Roy et al. [26] dealt with the same problem as those described above but in porous triangular cavities. In each considered case, these authors reported the values of the parameters that contribute to minimize the entropy generation.

In the last few years, the investigation on the entropy generation of the mixed convection confined spaces has also been extended considering the nature of the fluid, the presence of a magnetic field, or a thermal radiation. Goodarzi et al. [27] Investigated, using the Finite Volume Method, the effect of radiation on laminar and turbulent mixed convection heat transfer of a semi-transparent medium in a square enclosure. Aghaei et al. [28] performed numerical investigation, based on the Finite Volume Method, concerning the effect of horizontal and vertical elliptic baffles on the flow, heat transfer and entropy generation of a MWCNTs-water nanofluid. Yousef zadeh et al. [29] analyzed numerically, using the Finite Volume Method, entropy generation of mixed convection of either pure water or nanofluid flow in a circular obstacle inserted in an open cavity. Ebrahimi et al. [30] conducted the computational modeling of laminar mixed convection heat transfer and entropy generation of nanofluids inside a closed elbow-shaped cavity (CESC) using a finite volume method. Kashyap et al. [31] reported, using Multiple-relaxation-time lattice Boltzmann method, the effects of three different Prandtl number fluids $(\mathrm{Pr}=0.025$, 5.83 and 151) on convective heat transfer inside a closed 
square cavity with a square block positioned at its center. Khan et al. [32] applied the three-stage Lobatto technique implemented in MATLAB software to study the impacts of entropy along with non-linear radiation and viscous dissipation on mixed convection flow using an effective Prandtl model and comprising water and ethylene-based $\gamma-\mathrm{Al}_{2} \mathrm{O}_{3}$ particles over a stretched vertical sheet.

From this literature review, it appears that the numerical studies of mixed convection in confined spaces taking into account the impact of Prandtl number on the entropy generation are relatively scarce. Therefore, the problem has remained largely insufficiently exploited. For this purpose, the present work investigates the effects of the Prandtl number on entropy generation in mixed convection in a square cavity partially heated from below, with an adiabatic upper wall and cold vertical walls moving upward at a constant velocity.

\section{Physical problem and computational domain}

The schematic view of the geometric configuration investigated in the current study is shown in Fig. 1. It consists of a square cavity of side length $L$. The lateral walls of this cavity are maintained at a constant cold temperature $T_{c}$ and move upwards with a constant velocity $v_{w}$. A heat source of size $1=4 / 5 \mathrm{~L}$ is located at the center of the bottom wall of the cavity and maintained at a constant high temperature $T_{h}$. All remaining boundaries of the cavity are considered adiabatic. An illustrated mechanism allowing moving walls in relation to this geometric configuration can be found in Roy et al. [23].

\section{Governing equations}

The flow is steady, laminar and incompressible. Viscous dissipation is negligibly small and all other fluid properties

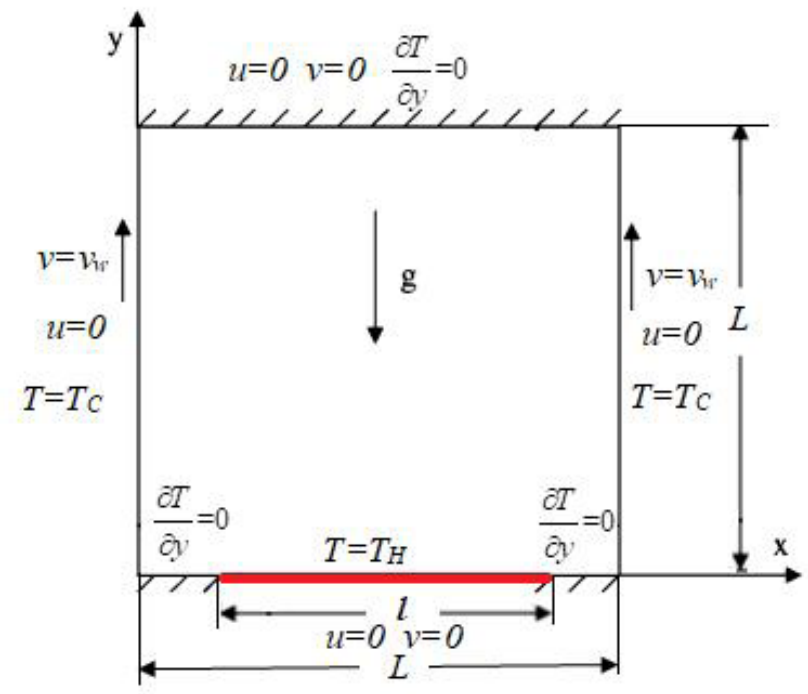

are assumed constant except the fluid density giving rise to the buoyancy forces (Boussinesq approximation [33]). Under the above assumptions, the governing equations of energy, vorticity, and stream function for a laminar incompressible fluid can be expressed respectively in dimensionless form as follows [34]:

$\frac{\partial \theta}{\partial \tau}+U \frac{\partial \theta}{\partial X}+V \frac{\partial \theta}{\partial Y}=\left(\frac{1}{\operatorname{Re}}\right) \frac{1}{\operatorname{Pr}}\left(\frac{\partial^{2} \theta}{\partial X^{2}}+\frac{\partial^{2} \theta}{\partial Y^{2}}\right)$,

$\frac{\partial \Omega}{\partial \tau}+U \frac{\partial \Omega}{\partial X}+V \frac{\partial \Omega}{\partial Y}=\left(\frac{1}{\mathrm{Re}}\right)\left[\frac{\partial^{2} \Omega}{\partial X^{2}}+\frac{\partial^{2} \Omega}{\partial Y^{2}}\right]+R i \frac{\partial \theta}{\partial X}$,

$\frac{\partial^{2} \Psi}{\partial X^{2}}+\frac{\partial^{2} \Psi}{\partial Y^{2}}=-\Omega$

The vorticity and the velocity components in the $X$ and $Y$ directions, respectively, are given by the following expressions:

$\Omega=\frac{\partial V}{\partial X}-\frac{\partial U}{\partial Y}, U=\frac{\partial \Psi}{\partial Y}, V=-\frac{\partial \Psi}{\partial X}$.

The dimensionless variables are defined as:

$$
\begin{aligned}
& X=\frac{x}{L}, Y=\frac{y}{L}, \theta=\frac{T-T_{c}}{\Delta T}, U=\frac{u}{v_{w}}, V=\frac{v}{v_{w}}, \\
& \tau=t \frac{v_{w}}{L}, P=\frac{p-p_{0}}{\rho v_{w}^{2}}, \Omega=\frac{L}{v_{w}}, \Psi=\frac{\psi}{L v_{w}} .
\end{aligned}
$$

The dimensionless numbers in these equations are, respectively, the Reynolds (Re), Prandtl (Pr) and Richardson (Ri) numbers and are defined by the following relationships:

$\operatorname{Re}=\frac{v_{w} L}{v}, \operatorname{Pr}=\frac{v}{\alpha}, \operatorname{Ri}=\frac{G r}{\operatorname{Re}^{2}}$,

where $\mathrm{Gr}$ is the Grashof number, $\mathrm{Gr}=\frac{g \beta \Delta T L^{3}}{v^{2}}$ and $\Delta T=T_{h}-T_{c}$ is the temperature difference.

In accordance with the aforementioned definition of the Grashof number, the Richardson number can be rewritten as:

$\mathrm{Ri}=\frac{g \beta \Delta T}{v^{2} \operatorname{Re}^{2}} L^{3}$.

Numerical solution of the previous equations is based on the following initial and boundary conditions:

- Initial conditions $(\tau=0)$ :

$$
\begin{aligned}
& 0<Y<1 \quad \& \quad 0<X<1: \\
& \theta=0 \quad \Psi=0 \Omega=0
\end{aligned}
$$

- Boundary conditions $(\tau>0)$ :

$$
\left.\begin{array}{l}
X=0 \\
X=1
\end{array}\right\} \& \quad 0 \leq Y \leq 1 \Rightarrow U=\theta=\Psi=0 \quad V=1,
$$

Fig. 1 A schematic diagram for the physical model 


$$
\begin{aligned}
& Y=0 \quad \& \quad 0 \leq X \leq(1-\varepsilon) / 2 \quad \&(1+\varepsilon) / 2 \leq X \leq 1 \\
& \Rightarrow U=V=\Psi=\frac{\partial \theta}{\partial Y}=0, \\
& Y=0 \quad \&(1-\varepsilon) / 2 \leq X \leq(1+\varepsilon) / 2 \\
& \Rightarrow U=V=\Psi=0 \quad \& \quad \theta=1, \\
& Y=1 \quad \& \quad 0 \leq X \leq 1 \\
& \Rightarrow U=V=\Psi=0 \quad \frac{\partial \theta}{\partial Y}=0 .
\end{aligned}
$$

Here $\varepsilon=l / L$ is the dimensionless length of the heated part of the bottom wall.

The dimensionless local and average Nusselt numbers along the bottom wall are written respectively as [35]:

$$
\mathrm{Nu}(X)=-\left.\frac{\partial \theta}{\partial Y}\right|_{Y=0}
$$

and

$$
\overline{\mathrm{Nu}}=\frac{1}{\varepsilon} \int_{\frac{1-\varepsilon}{2}}^{\frac{1+\varepsilon}{2}} \mathrm{Nu}(X) d X .
$$

\section{Entropy generation}

\subsection{Entropy generation equation}

In accordance with the concept of the local thermodynamic equilibrium with the linear transport theory [1], the entropy generation relation is given by:

$$
\begin{aligned}
& S_{\text {gen }}=\frac{k}{T_{\text {ref }}^{2}}\left\{\left(\frac{\partial T}{\partial x}\right)^{2}+\left(\frac{\partial T}{\partial y}\right)^{2}\right\}+ \\
& \frac{\mu}{T_{\text {ref }}}\left[2\left(\frac{\partial u}{\partial x}\right)^{2}+2\left(\frac{\partial v}{\partial y}\right)^{2}+\left(\frac{\partial u}{\partial y}+\frac{\partial v}{\partial x}\right)^{2}\right] .
\end{aligned}
$$

In non-dimensional form, it is expressed as follows in Eq. (12):

$$
\begin{aligned}
& S_{\text {gen }}=\underbrace{s_{1}\left\{\left(\frac{\partial \theta}{\partial X}\right)^{2}+\left(\frac{\partial \theta}{\partial Y}\right)^{2}\right\}}_{S_{t h}}+ \\
& \underbrace{S_{2}\left[2\left(\frac{\partial U}{\partial X}\right)^{2}+2\left(\frac{\partial V}{\partial Y}\right)^{2}+\left(\frac{\partial U}{\partial Y}+\frac{\partial V}{\partial X}\right)^{2}\right]}_{S_{f f}},
\end{aligned}
$$

where the entropy generation due to heat transfer irreversibility is $S_{t h}$, the entropy generation due to fluid friction irreversibility is $S_{f f}$ and the irreversibility distribution ratios are:

$s_{1}=k\left(\frac{\Delta T}{T_{\text {ref }}}\right)^{2} \frac{1}{L^{2}} ; s_{2}=\frac{\mu}{T_{\text {ref }}}(v \operatorname{Re})^{2} \frac{1}{L^{4}}$.

Here $T_{\text {ref }}=\left(T_{h}+T_{c}\right) / 2$ is the reference temperature.
The total entropy generation may be expressed by integrating Eq. (10) within the whole cavity.

$$
\overline{S_{g e n}}=\underbrace{\int_{0}^{1} \int_{0}^{1} S_{t h} d X d Y}_{\overline{S_{t h}}}+\underbrace{\int_{0}^{1} \int_{0}^{1} S_{f f} d X d Y}_{\overline{S_{f f}}}
$$

\subsection{Bejan number}

The local Bejan number $(\mathrm{Be})$ is defined as the ratio of the entropy generation due to heat transfer to the total entropy generation due to heat transfer and fluid friction, it is expressed as:

$\mathrm{Be}=\frac{S_{t h}}{S_{g e n}}$.

The average value of this number is given by:

$$
\overline{B e}=\frac{\overline{S_{t h}}}{\overline{S_{g e n}}}
$$

\section{Numerical procedure and code validation \\ 5.1 Numerical procedure}

The above-mentioned governing equations, Eqs. (1-4) subject to the given boundary conditions, Eqs. (6-9) were discretized by the finite difference method. Temporal discretization was achieved using the Runge-Kutta fourth-order method (R.K.4) with the time step $\Delta \tau=10^{-5}$ for each iteration. The convective terms in Eqs. (1) and (2) were discretized with a third-order upwind scheme as proposed by Kawamura et al. [36]. The diffusive terms, as well as the terms including the first derivatives, were discretized by a fourth-order accurate scheme. An iterative procedure based on the successive Non Linear Over Relaxation method (NLOR) was used to solve the discredited stream function equation Eq. (3). A convergence criterion for the stream function was imposed at every stage of the RungeKutta procedure. Once the dimensionless velocities $(U, V)$ and temperatures $(\theta)$ are determined, the average Nusselt number along the hot part of the bottom wall Eq. (10) and the characteristics of the entropy generation are computed using Eqs. (12) to (14) and (16). Finally, it should be mentioned that all the integrals Eqs. (10) and (14) are evaluated using Simpson's rule. An in-house FORTRAN code, with a double precision accuracy, has been developed for solving the systems of the discretized equations.

\subsection{Grid independency}

Numerical tests have been made to ensure the accuracy of results for the grid used in this study. Four grid sizes $(41 \times 41$; $81 \times 81 ; 101 \times 101$ and $161 \times 161)$ have been considered. These 
numerical tests are carried out for the case of Reynolds number $\mathrm{Re}=100$, Prandtl number $\mathrm{Pr}=0.6992$ (air at $453 \mathrm{~K}$ ) and Richardson number $\mathrm{Ri}=5$ and 30 . Table 1 shows the convergence of the average Nusselt number, while Table 2 shows the average of the total entropy generation and Bejan number. It should be noted that the maximum relative error does not exceed $2 \%$ between the grid sizes of $81 \times 81$ and $101 \times 101$ compared to the grid size of $161 \times 161$. Therefore, it was decided to use a non-uniform grid with $101 \times 101$ grid points for all calculations allowing a balance between accuracy and CPU time.

\subsection{Validation}

In order to ensure the effectiveness of the developed code, a first validation was carried out to compare the values of the average Nusselt number $(\mathrm{Nu})$ obtained in the classic case of natural convection occurring in a square cavity with differentially heated vertical sides and insulated horizontal walls. Table 3 shows this comparison for different Rayleigh numbers when the Prandtl number is set at 0.71 .

A complementary validation, which considers the same problem in the same geometrical configuration, but this time the comparison relates to the total entropy generation and the average Bejan number. The results are shown in Table 4.

\section{Results and discussion}

\subsection{Detailed data associated with the problem}

The present numerical study investigates the fluid flow and the mixed convection heat transfer in a square cavity partially heated from below with a moving cooled vertical sidewalls. Numerical simulations have been performed for different Richardson numbers (Ri) calculated on the basis of length of the cavity $(L)$. A great deal of interest is being focused on the effect of the Prandtl number (Pr) on the fluid flow, heat transfer and entropy generation inside the cavity considering three working fluids, the most encountered in

Table 1 Grid independence test: average Nusselt number for $\operatorname{Re}=100, \operatorname{Pr}=0.6992$ and $\mathrm{Ri}=5$ and 30

\begin{tabular}{lcccc}
\hline & $41 \times 41$ & $81 \times 81$ & $101 \times 101$ & $161 \times 161$ \\
\hline $\mathrm{Ri}=5$ & 6.409972 & 6.501360 & 6.519890 & 6.554256 \\
$\mathrm{Ri}=30$ & 7.760660 & 8.235425 & 8.280651 & 8.351396 \\
\hline
\end{tabular}

Table 2 Grid independence test: average Entropy generation and Bejan number for $\mathrm{Re}=100, \operatorname{Pr}=0.6992$ and $\mathrm{Ri}=5$ and 30

\begin{tabular}{cccccc}
\hline $\mathrm{Ri}$ & & $41 \times 41$ & $81 \times 81$ & $101 \times 101$ & $161 \times 161$ \\
\hline \multirow{2}{*}{5} & $\overline{S_{\text {gen }}}$ & 0.1413722 & 0.14011485 & 0.1398440 & 0.139495 \\
& $\overline{B_{e}}$ & 0.99991734 & 0.999815 & 0.99976241 & 0.999604 \\
\multirow{2}{*}{30} & $\overline{S_{\text {gen }}}$ & 5.5527665 & 5.45867439 & 5.4468174 & 5.432849 \\
& $\overline{B_{e}}$ & 0.99996553 & 0.999945 & 0.99993304 & 0.999896 \\
\hline
\end{tabular}

Table 3 Comparison of reported values of the average Nusselt number with present results

\begin{tabular}{ccccc}
\hline $\mathrm{Ra}$ & $\begin{array}{c}\text { De Vahl Davis } \\
\text { and Jones [37] }\end{array}$ & $\begin{array}{c}\text { De Vahl Davis } \\
{[38]}\end{array}$ & $\begin{array}{c}\text { Balam and } \\
\text { Gupta [39] }\end{array}$ & $\begin{array}{c}\text { Present } \\
\text { work }\end{array}$ \\
\hline $10^{3}$ & 1.116 & 1.117 & 1.119 & 1.119 \\
$10^{4}$ & 2.242 & 2.238 & 2.260 & 2.250 \\
$10^{5}$ & 4.564 & 4.509 & 4.645 & 4.592 \\
$10^{6}$ & 9.035 & 8.817 & 9.184 & 9.001 \\
\hline
\end{tabular}

Table 4 Comparison of reported values of the total entropy generation and the average Bejan number with present results $\left(\operatorname{Pr}=0.71, \varphi=10^{-4}\right)$

\begin{tabular}{ccccccc}
\hline Ra & & $\begin{array}{c}\text { Ilis et al. } \\
\text { [40] }\end{array}$ & $\begin{array}{c}\text { Oliveski } \\
\text { et al. [41] }\end{array}$ & $\begin{array}{c}\text { Masvik et } \\
\text { al. [42] }\end{array}$ & $\begin{array}{c}\text { Jassim et } \\
\text { al. [43] }\end{array}$ & $\begin{array}{c}\text { Present } \\
\text { work }\end{array}$ \\
\hline \multirow{2}{*}{$10^{3}$} & $\overline{S_{\text {gen }}}$ & 1.20 & 1.16 & 1.15 & 1.152 & 1.153 \\
& $\overline{B_{e}}$ & 0.96 & 0.96 & 0.97 & 0.965 & 0.97 \\
& $\overline{S_{\text {gen }}}$ & 23.50 & 23.87 & 23.27 & 23.27 & 23.94 \\
$10^{5}$ & $\overline{B_{e}}$ & 0.20 & 0.183 & 0.194 & 0.199 & 0.208 \\
\hline
\end{tabular}

studies, namely mercury $(\operatorname{Pr}=0.0251)$, air $(\operatorname{Pr}=0.7296)$ and pure water $(\operatorname{Pr}=6.263)$. The reference values of their thermo-physical properties have been taken from Cengel and Ghajar [44] at the same bulk temperature $T_{r e f}=298 \mathrm{~K}$ and are listed in Table 5. Furthermore, the Reynolds number $(\mathrm{Re})$ and the temperature difference $\Delta T$ are kept constant at $10^{2}$, and $10 \mathrm{~K}$ respectively.

On the other hand, we found it necessary that all geometric configurations will have the same cavity length $L$ for each number of Prandtl considered in this study, so we can be sure to compare what is comparable. The length $L$ varies between two limits. The lower limit is fixed at $5.10^{-3} \mathrm{~m}$, as suggested by Moon and Chung [16], while the upper limit will depend on getting the suitable stable and stationary flow regime for each Prandtl number. This one is supposed to be achieved once the average Nusselt number becomes constant and independent of time. We have fixed once and for all, in Table 6, these limits as well as their corresponding Richardson numbers, for the different fluids considered in this investigation.

\subsection{Effect of Ri and Pr on the thermal and flow fields}

The flow and heat transfer characteristics have been presented and analysed using stream traces and isotherms. Figs. 2 to 4 depicts, for the three fluids considered, the stream traces superimposed on the isotherms, on the left for the lower limit $(L=0.005 \mathrm{~m})$, and on the right for the upper limit ( $L$ depends on the type of fluid).

We can distinguish two different behaviour of the fluid flow through the cavity according to the value of the Richardson number. For low values of this parameter, the 
Table 5 Thermo-physical properties of working fluids at $298 \mathrm{~K}$ from [44]

\begin{tabular}{lccccc}
\hline & $\begin{array}{c}\text { Density } \\
\rho\left(\mathrm{kgm}^{-3}\right)\end{array}$ & $\begin{array}{c}\text { Thermal conductivity } \\
\mathrm{k}\left(\mathrm{Wm}^{-1} \mathrm{~K}^{-1}\right)\end{array}$ & $\begin{array}{c}\text { Dynamic vicosity } \\
\mu\left(\mathrm{kgm}^{-1} \mathrm{~s}^{-1}\right)\end{array}$ & $\begin{array}{c}\text { Thermal expansion } \\
\text { coefficient } \beta\left(\mathrm{K}^{-1}\right)\end{array}$ & $\begin{array}{c}\text { Prandtl } \\
\text { number }(\operatorname{Pr})\end{array}$ \\
\hline $\mathrm{Hg}$ & 13534 & 8.51533 & $1.53410^{-3}$ & $1.8110^{-4}$ & 0.0251 \\
$\mathrm{Air}$ & 1.184 & 0.02551 & $1.84910^{-5}$ & $3.355710^{-3}$ & 0.73 \\
$\mathrm{H}_{2} \mathrm{O}$ & 997.1 & 0.5948 & $8.90510^{-4}$ & $2.59410^{-4}$ & 6.263 \\
\hline
\end{tabular}

Table 6 Limit values of the length $L$ of the cavity with the corresponding Richardson numbers for the working fluids

\begin{tabular}{lcccc}
\hline & $L(\min )$ & $L(\max )$ & $\mathrm{Ri}(\min )$ & $\mathrm{Ri}(\max )$ \\
\hline Water $(\operatorname{Pr}=6.263)$ & 0.005 & 0.019 & 0.4 & 21.9 \\
Air $(\operatorname{Pr}=0.7263)$ & 0.005 & 0.1 & 0.017 & 135 \\
Mercury $(\operatorname{Pr}=0.0251)$ & 0.005 & 0.0085 & 17.3 & 85 \\
\hline
\end{tabular}

flow consists of two counter-rotating cells. The viscous forces due to the upward movement of the side walls causes the fluid to rise along the side walls, bypass the upper wall and descend again along the centre of the cavity. In this case, the heat flow recovered by the fluid from the heat source is directly discharged through the lower portion of the vertical walls. Note that the current behaviour was not observed in the case of mercury. For high values of the Richardson number, the flow consists of four cells, two counter-rotating cells located in the centre of the cavity due to buoyancy forces, and the other two, also counter-rotating due to viscous forces, are weak and adjacent to the lateral sidewalls. Inside each of them, two minor vortices appear at the bottom and top corners. In this instance, all the heat from the hot source is propagated through the centre of the cavity. These observations are similar to those obtained by Biswas and Manna [45] with the same geometrical configuration. However, concerning the effect of the Prandtl number, we observe, for the forced convection-dominated regime, that the sidewall's thermal boundary layer is thinner in the case of water than in that of air. In addition, and in the same circumstances, it should be noted that the penetration of cold fluid from the top and which flows along the central part of the cavity is relatively greater.

\subsection{Effect of Pr and Ri on the Nusselt number}

The effect of the Prandtl and Richardson numbers on the average Nusselt number is shown in Figs. 5, 6 and 7. Fig. 3 presents the evolution of the average Nusselt number for the working fluids within the limits already mentioned above. It is observed that after initial fluctuations, the average Nusselt number become steady. Their duration

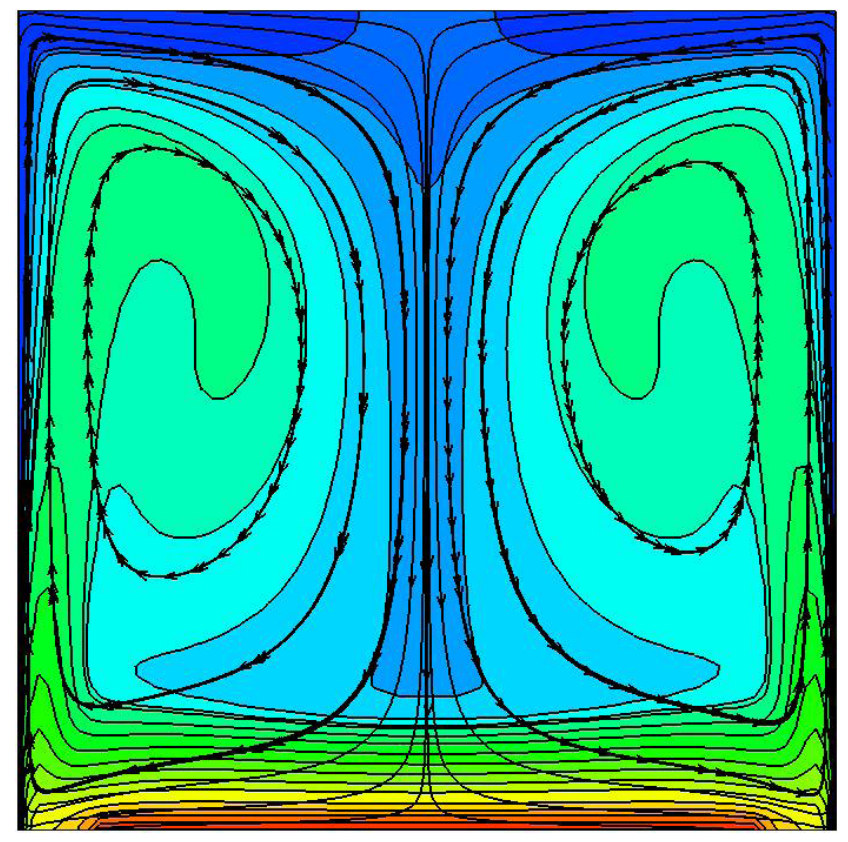

(a)

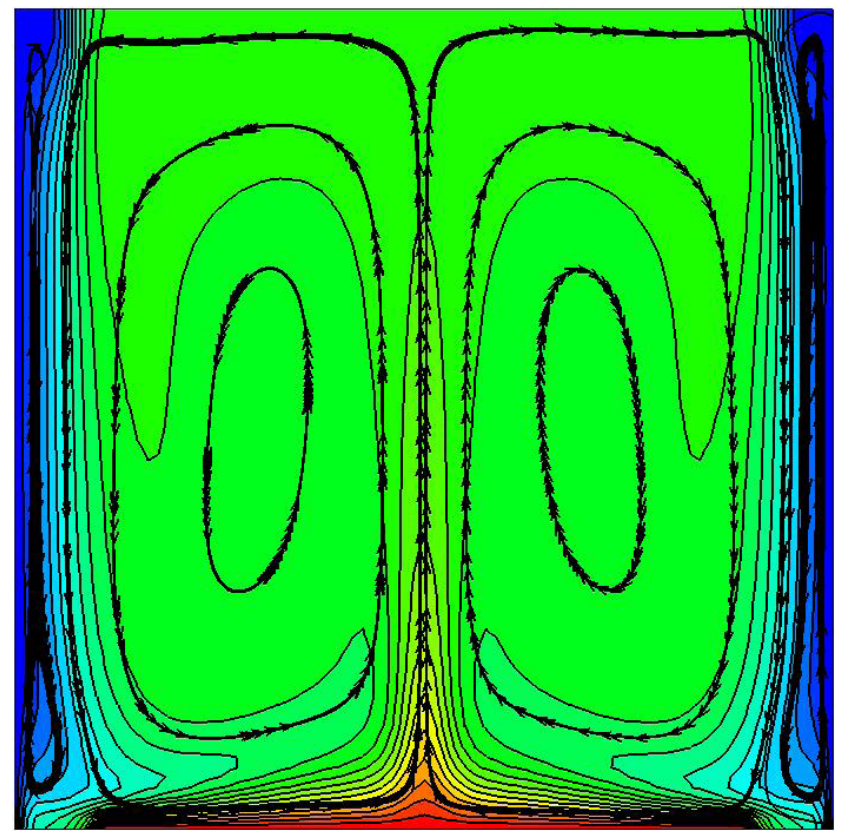

(b)

Fig. 2 Stream traces superimposed on the isotherms for water $(\operatorname{Pr}=6.263)$; (a) $\mathrm{Ri}=0.4(L=0.005 \mathrm{~m})$; (b) $\mathrm{Ri}=21.9(L=0.019 \mathrm{~m})$ 


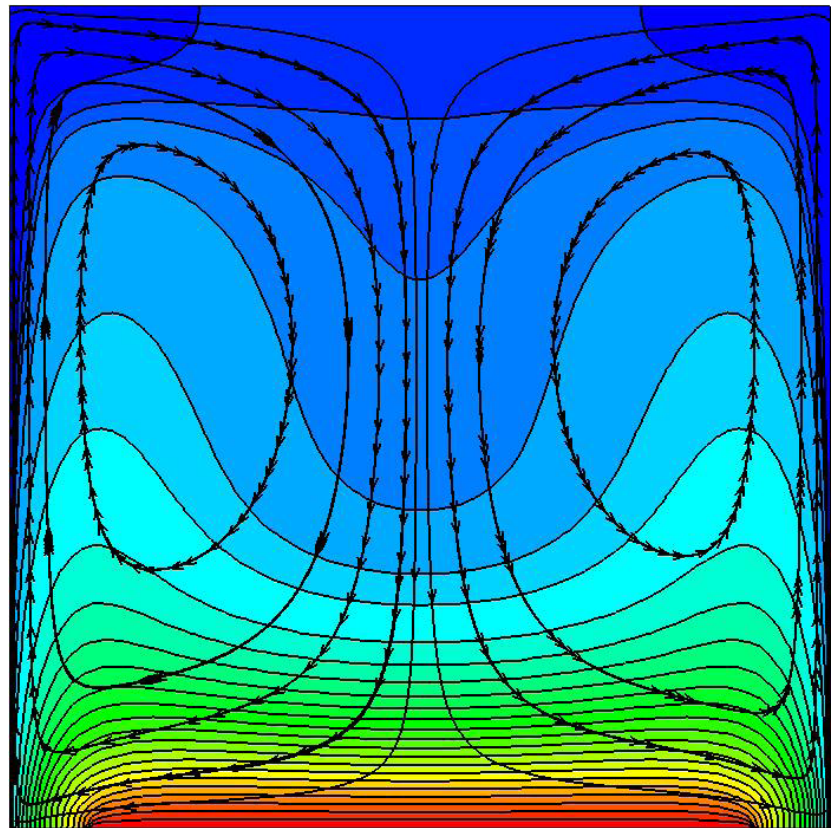

(a)

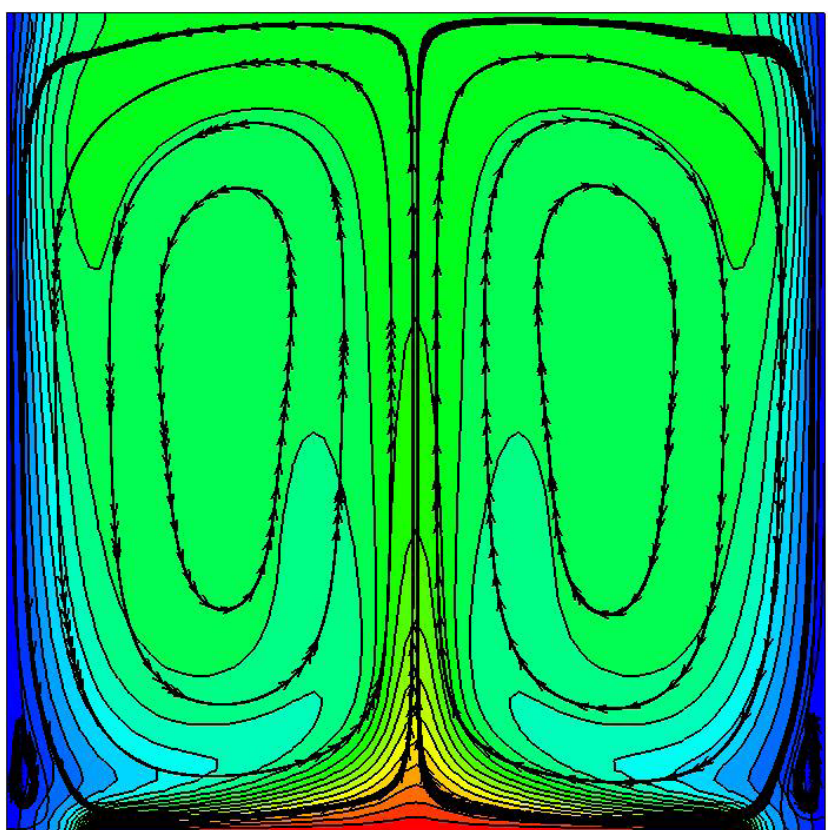

(b)

Fig. 3 Stream traces superimposed on the isotherms for air $(\operatorname{Pr}=0.7296) ;(a) \mathrm{Ri}=0.017(L=0.005 \mathrm{~m}) ;(\mathrm{b}) \mathrm{Ri}=135(L=0.1 \mathrm{~m})$

and amplitude continue to increase significantly as the Ri increase, particularly for water and mercury. On the other hand, we can also see that the gap between the values of the average Nusselt number is significantly higher in the case of air $(\operatorname{Pr} \sim 1)$, than in the case of water $(\operatorname{Pr} » 1)$, or in the case of mercury $(\operatorname{Pr} \ll 1)$.

Fig. 6 provides typical variation of the average Nusselt number as a function of Ri number for water, air, and

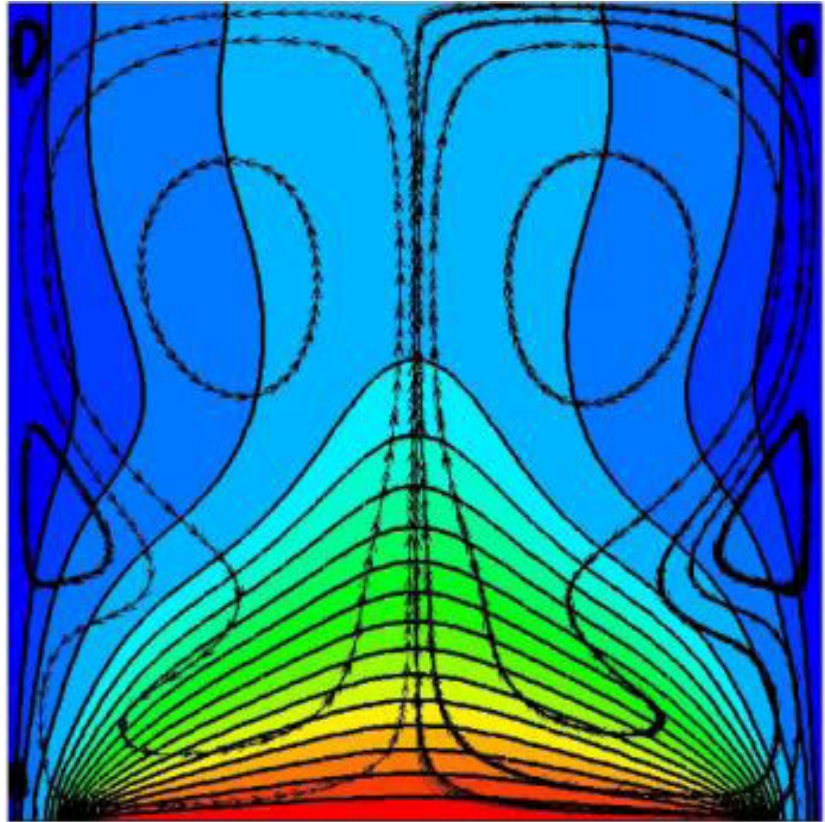

(a)

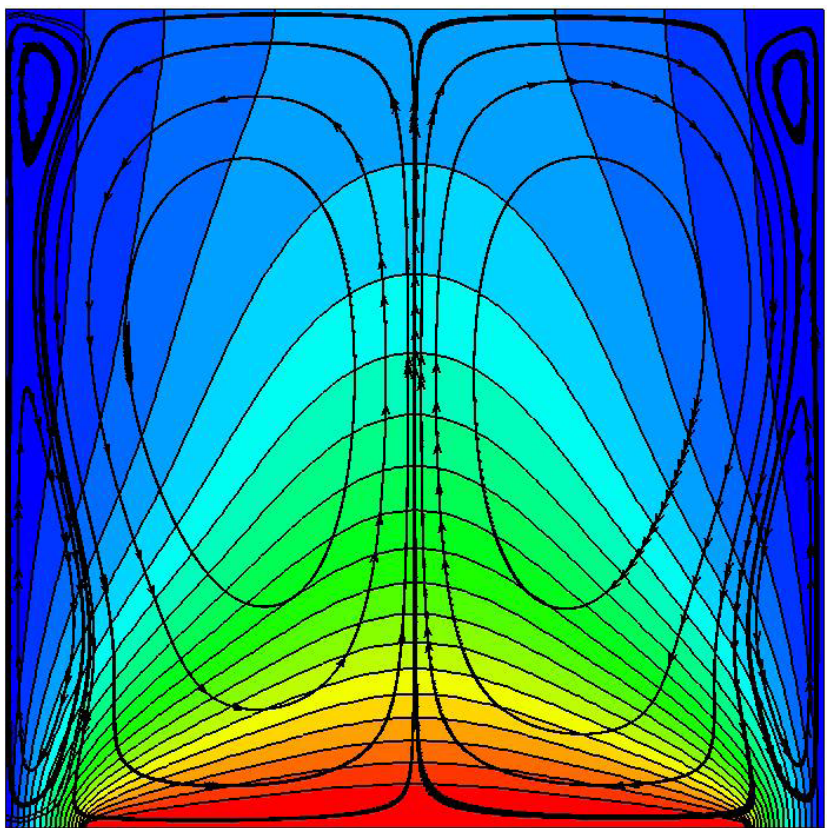

(b)

Fig. 4 Stream traces superimposed on the isotherms for mercury $(\operatorname{Pr}=0.0251) ;(a) \mathrm{Ri}=17.3(L=0.005 \mathrm{~m}) ;($ b) $\mathrm{Ri}=85(L=0.0085 \mathrm{~m})$

mercury. For mercury (Fig. 5 (c)), the average Nusselt number increases with increasing $\mathrm{Ri}$, while for water and air, it increases, then undergoes a significant reduction during the transition from the flow characterized by two cells to that characterized by four cells (bifurcation), and then start over increasing.

To illustrate more clearly the effect of the Prandtl number on the heat exchange at the heated wall, Fig. 6 (a), (b) and (c) 


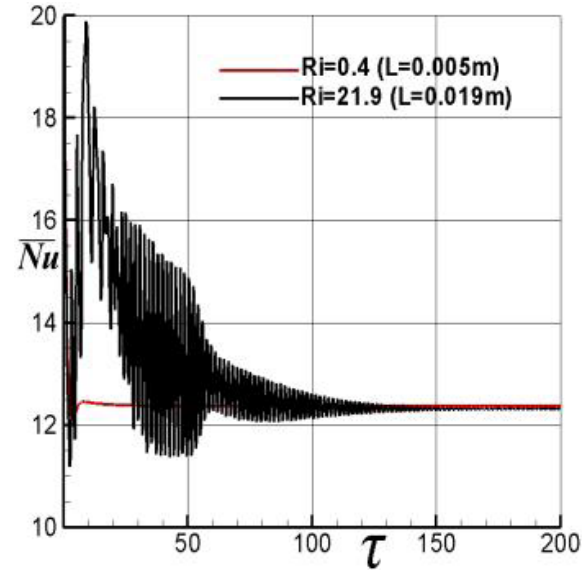

(a)

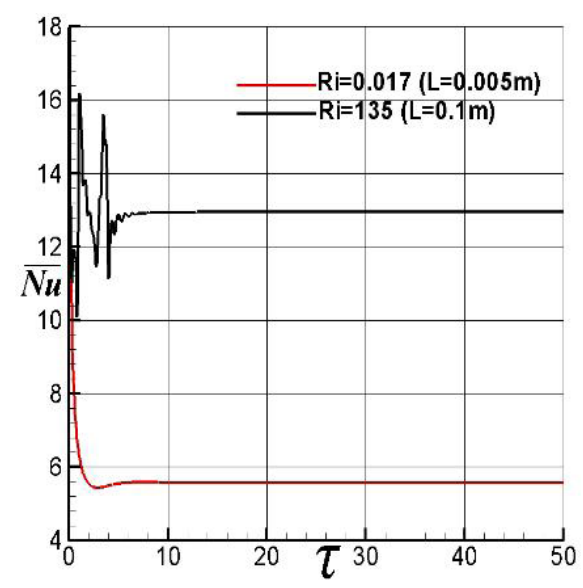

(b)

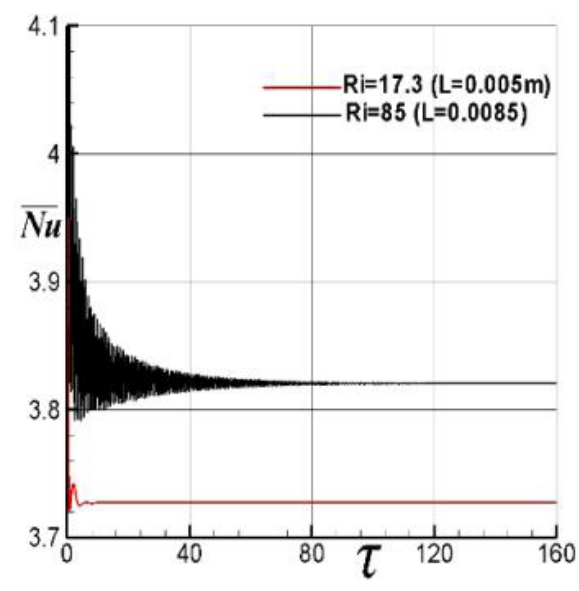

(c)

Fig. 5 Evolution of the average Nusselt number (a) for water, (b) for air and (c) for mercury

are brought together in Fig. 7. It can be seen that the average Nusselt number increases with the increase of Pr, regardless of the value of Ri. This could be explained by the fact that as the Prandtl number increases, the thermal diffusion becomes, more and more reduced; the temperature gradients near the heated wall become much more significant, which implies an

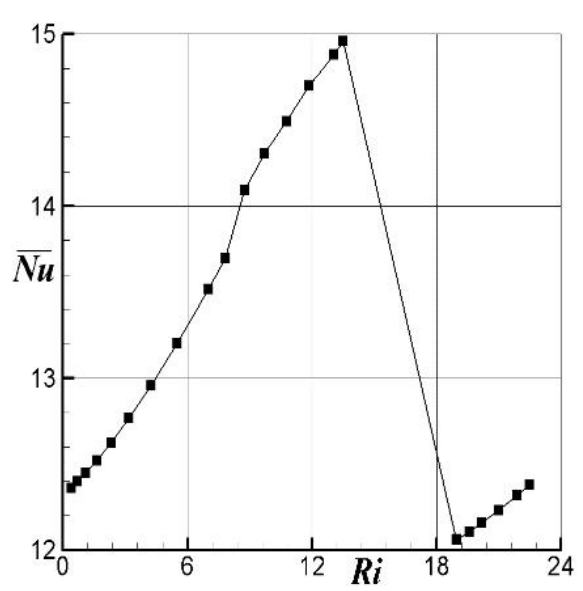

(a)

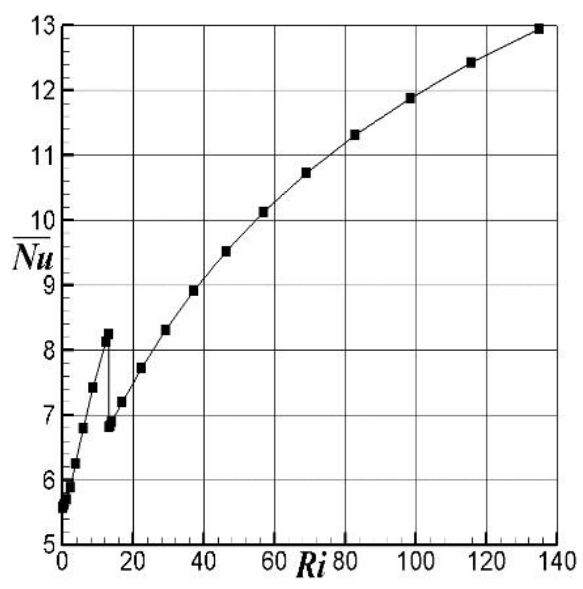

(b)

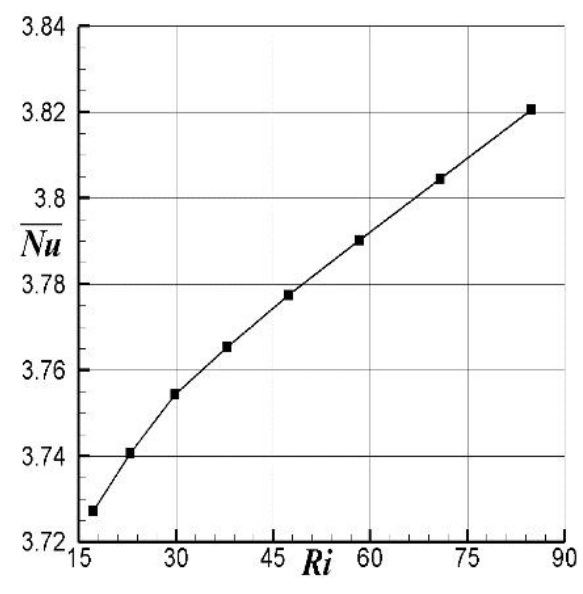

(c)

Fig. 6 Average Nusselt number versus the Richardson number, (a) for water, (b) for air and (c) for mercury

increase in the average Nusselt number. Similar results were obtained by Cheng [13] and, Moallemi and Jang [46].

\subsection{Effect of Pr and Ri on the entropy generation}

The total entropy generation, the entropy generation due to heat transfer and the entropy generation due to fluid 


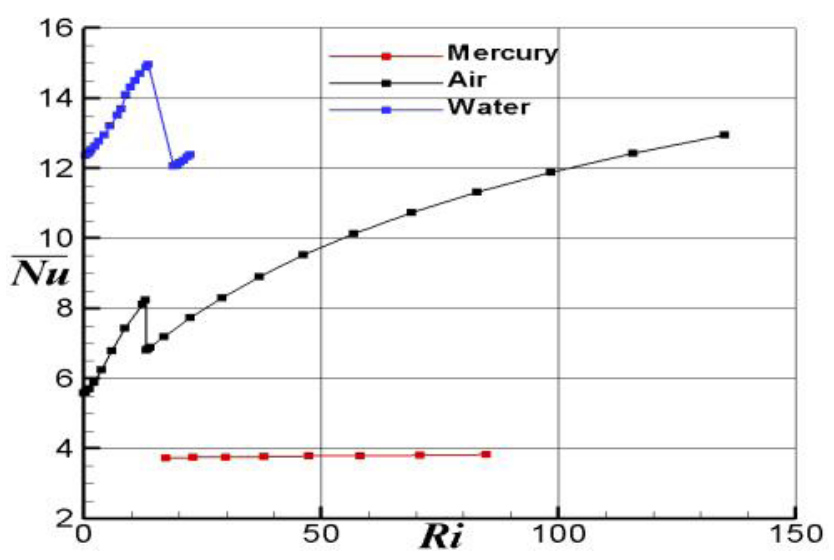

Fig. 7 Comparison of the average Nusselt number for the working fluids versus the Richardson number

friction for water $(0.4 \leq \mathrm{Ri} \leq 21.9)$, air $(0.017 \leq \mathrm{Ri} \leq 135)$ and mercury $(17.3 \leq \mathrm{Ri} \leq 85)$ are presented in Figs. 8-13, respectively.

As seen from these figures, it is possible to make, qualitatively some observations. One is that the entropy generation contours follow the isotherms trend. The second is that the total entropy generation is near that of the entropy generation due to heat transfer. Therefore, the entropy generation due to fluid friction is quite insignificant in relation to the entropy generation due to the heat transfer. As a result, the average Bejan number is close to one, and thus we decided it was more relevant not to include its contours in this paper Another is that the bulk of entropy generation comes from each end of the heated source, while the entropy generation due to fluid friction develops along the lateral moving walls. Very recently, a similar point was made by Monaledi and Makinde [47]. All of these comments are valid for all values considered of Prandtl and Richardson numbers.

In order to assess objectively and quantitatively the impact of the Prandtl and Richardson numbers, the logarithm of the average entropy generation versus $\mathrm{Ri}$, for the three working fluids, is presented in Fig. 14. It is worth noting that the average total entropy generation decreases by increasing the Richardson number. Ebrahimi et al. [30] also reported this significant result. We also observe that the average total entropy generation is found to be high for mercury $(\operatorname{Pr}=0.0251)$ and water $(\operatorname{Pr}=6.263)$ compared to that of air $(\operatorname{Pr}=0.7296)$.

In order to highlight the very low values of the average entropy generation due to fluid friction for the different Prandtl numbers, we have displayed in Fig. 15 the variation of the logarithm of this one versus Ri. It is interesting to observe that the average entropy generation due to fluid

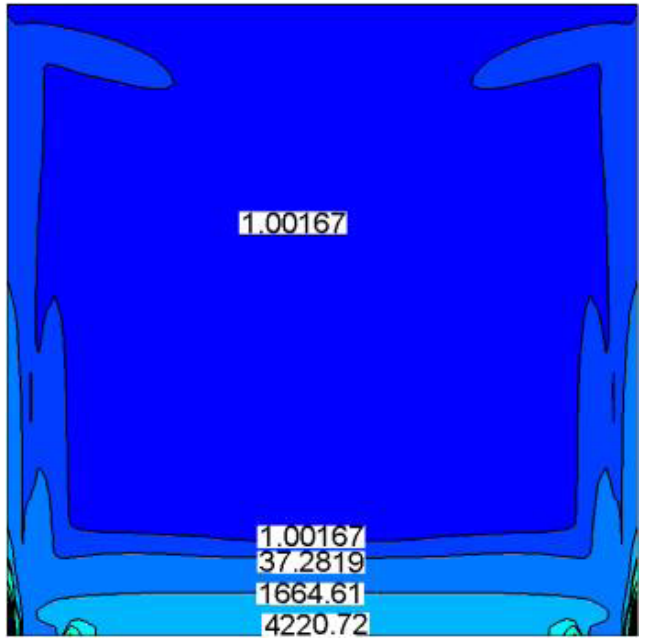

(a)

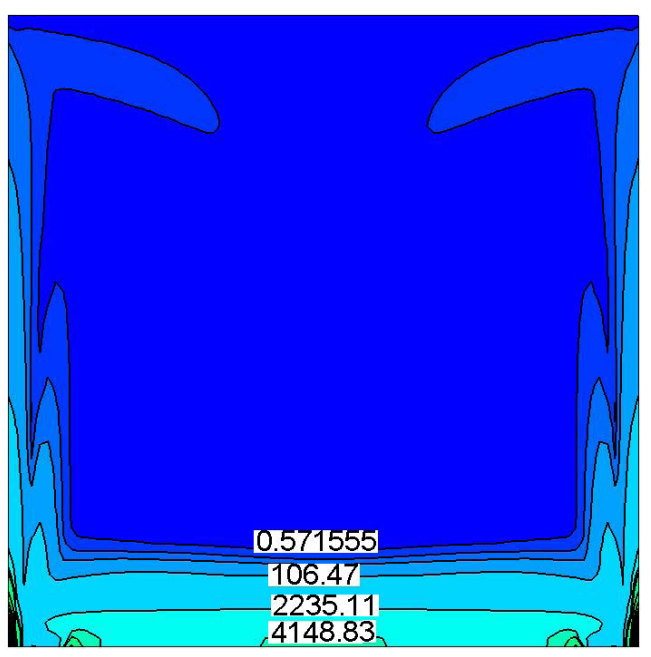

(b)

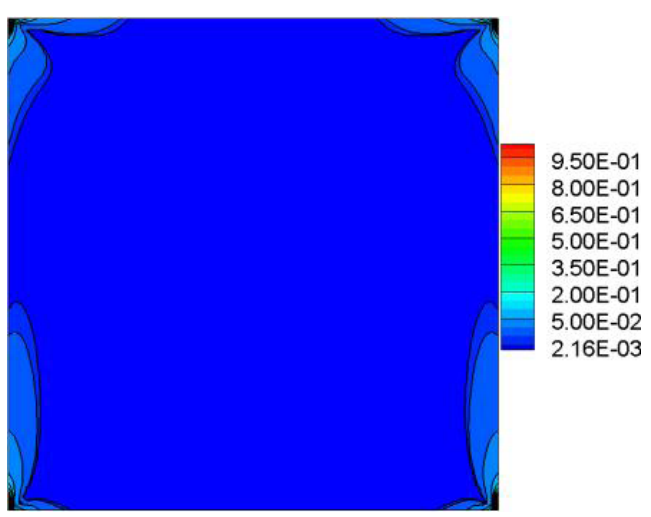

(c)

Fig. 8 (a) Contour of the total entropy generation $S_{\text {gen }}$, (b) the entropy generation due to heat transfer $S_{t h}$, and (c) the entropy generation due to fluid friction $S_{f f}$ for water at $\mathrm{Ri}=0.4$

friction follows a similar trend as the average total entropy generation. The average total entropy generation scale is 


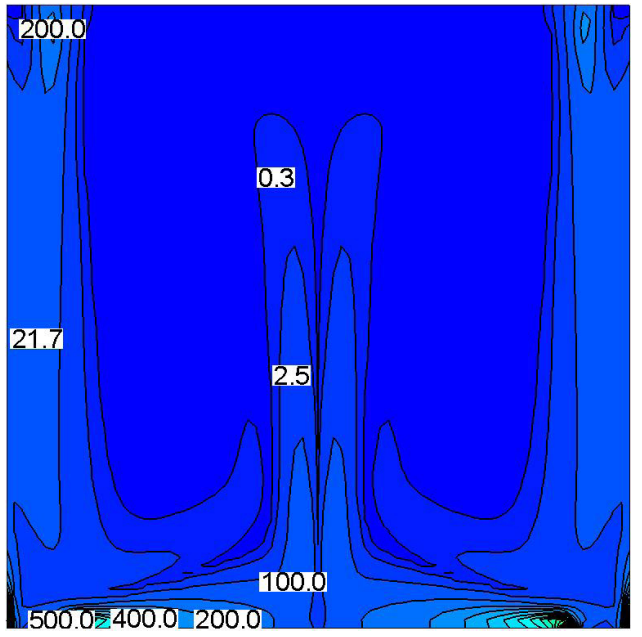

(a)

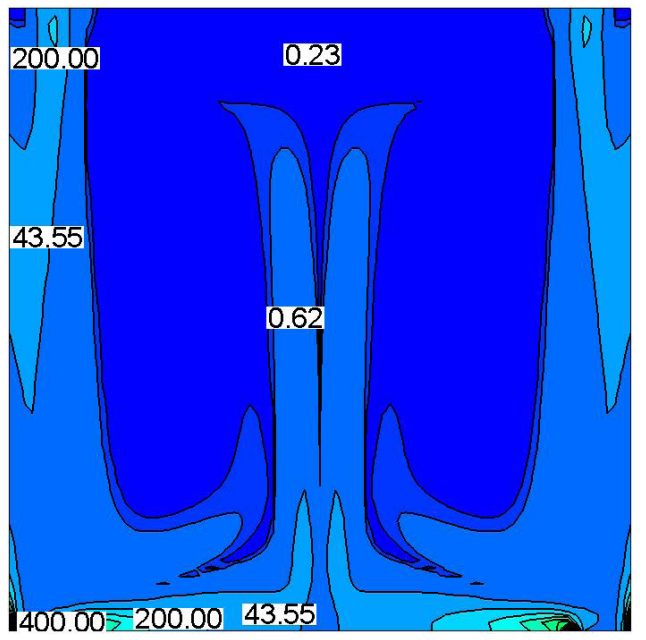

(b)

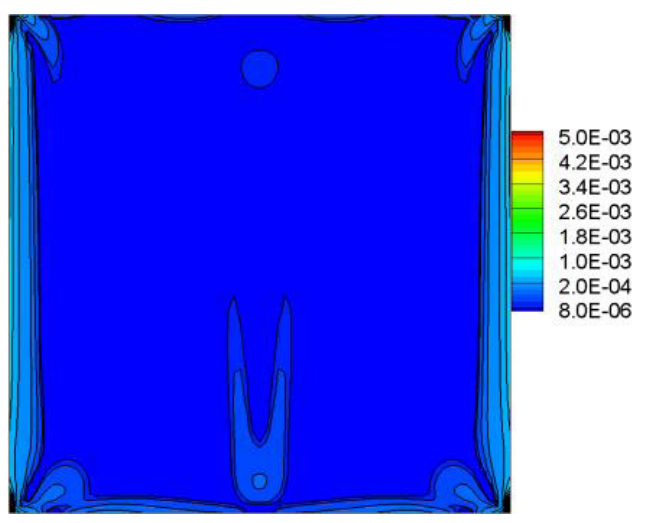

(c)

Fig. 9 (a) Contour of the total entropy generation $S_{g e n}$, (b) the entropy generation due to heat transfer $S_{t h}$, and (c) the entropy generation due to fluid friction $S_{f f}$ for water at $\mathrm{Ri}=21.9$

between $10^{-2}$ and $10^{4}$ while the average entropy generation due to fluid friction is between $10^{-6}$ and $10^{1}$. This result confirms the commonly adopted hypothesis, which states

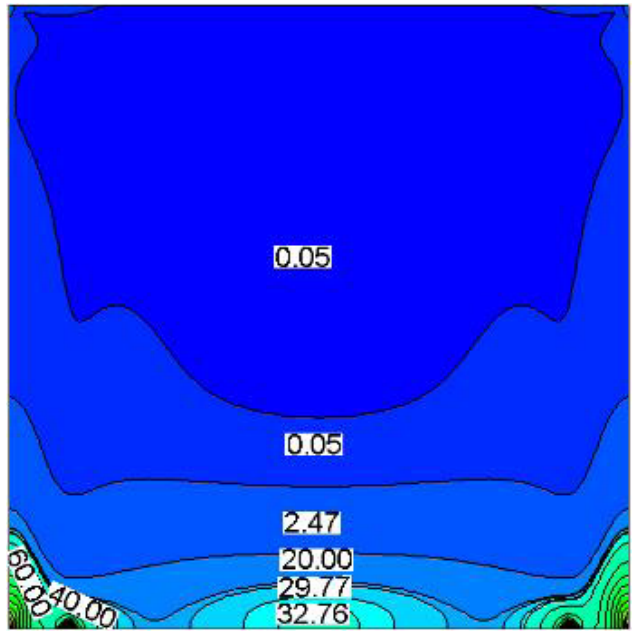

(a)

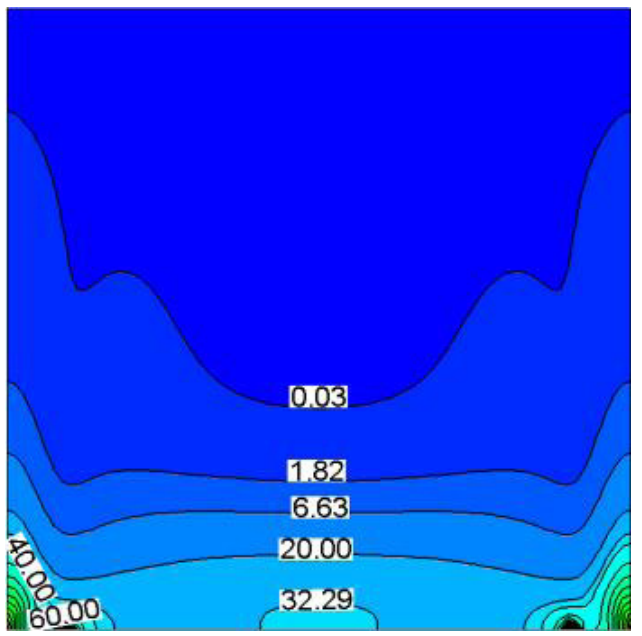

(b)

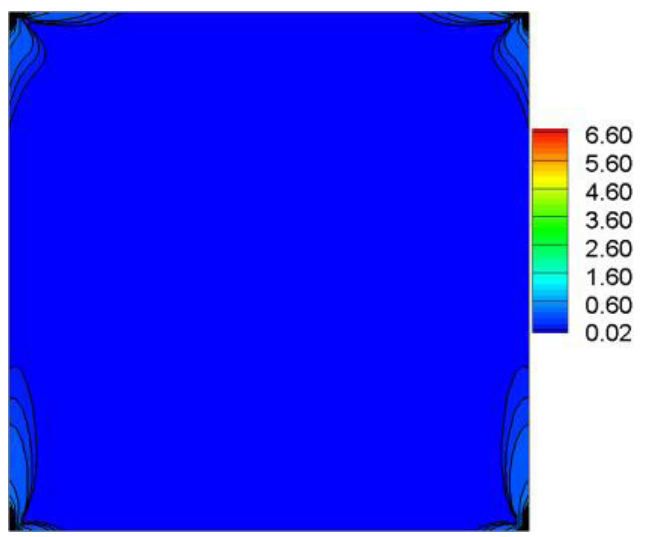

(c)

Fig. 10 (a) Contour of the total entropy generation $S_{g e n}$, (b) the entropy generation due to heat transfer $S_{t h}$, and (c) the entropy generation due to fluid friction $S_{f f}$ for air at $\mathrm{Ri}=135$

that the viscous dissipation function is neglected in the energy transport equation. 


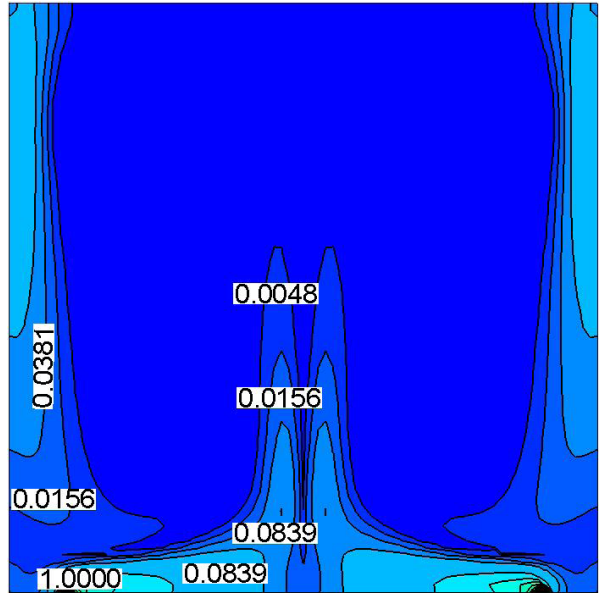

(a)

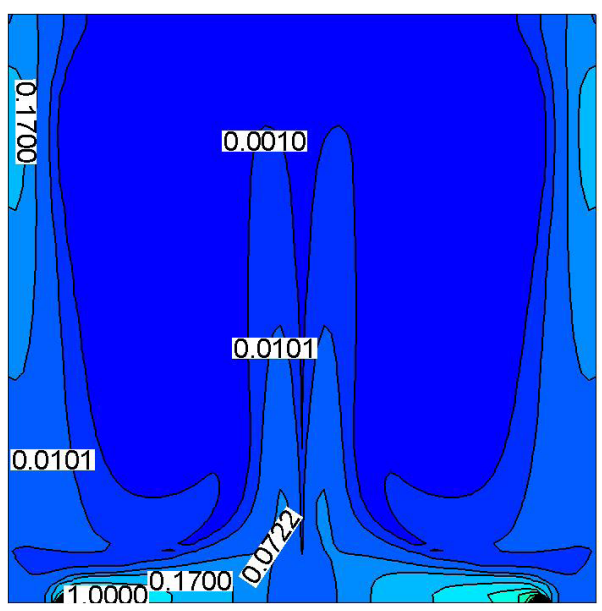

(b)

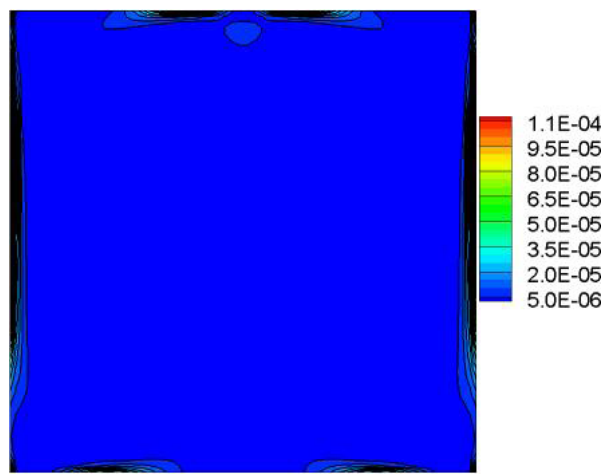

(c)

Fig. 11 (a) Contour of the total entropy generation $S_{g e n}$, (b) the entropy generation due to heat transfer

$S_{t h}$, and (c) the entropy generation due to fluid friction $S_{f f}$ for air at $\mathrm{Ri}=0.017$

As seen in Figs. 8-13 the total entropy generation is predominately within the lower corners of the sidewalls of the cavity as well as at both ends of the heat source located in the mid-section of the bottom cavity wall. To specify more accurately the active sites of the energy losses, the profiles

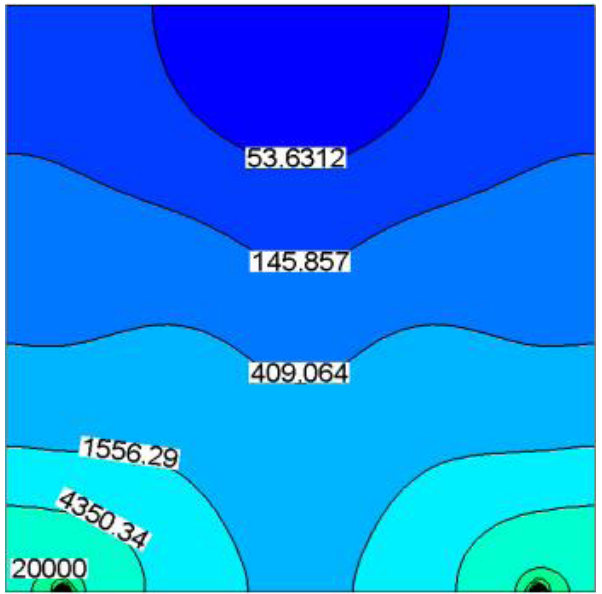

(a)

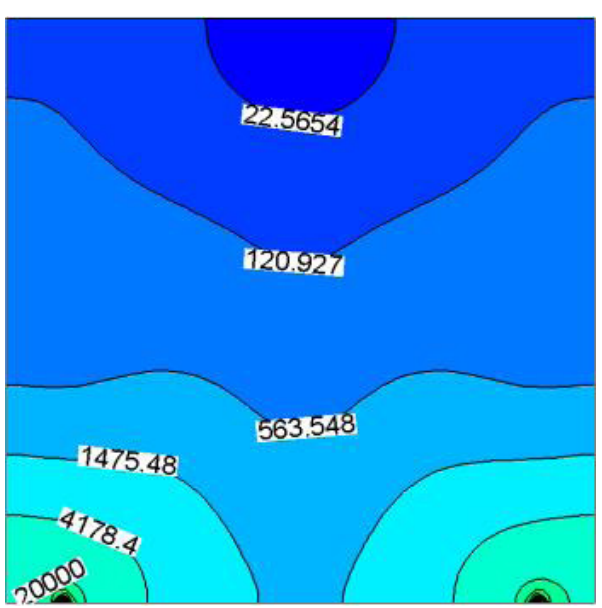

(b)

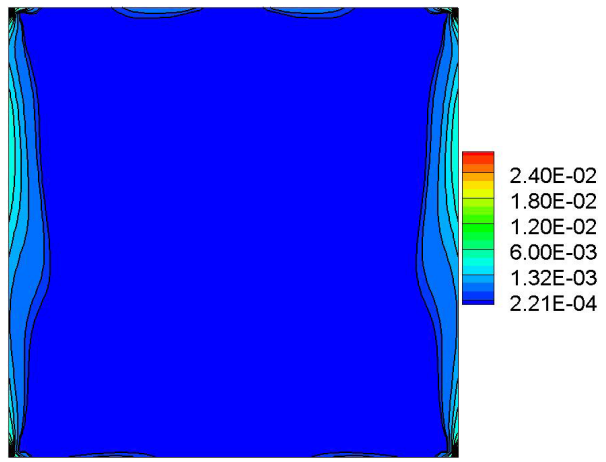

(c)

Fig. 12 (a) Contour of the total entropy generation $S_{g e n}$, (b) the entropy generation due to heat transfer $S_{t h}$, and (c) the entropy generation due to fluid friction $S_{f f}$ for mercury at $\mathrm{Ri}=17.3$

of the entropy generation on the bottom wall are plotted in Fig. 16 for (a) water $(\operatorname{Pr}=6.263)$, (b) air $(\operatorname{Pr}=0.7296)$ and (c) mercury $(\mathrm{Pr}=0.0251)$.

It would seem, in general terms, that the entropy generation contours have almost the same shape. However, 


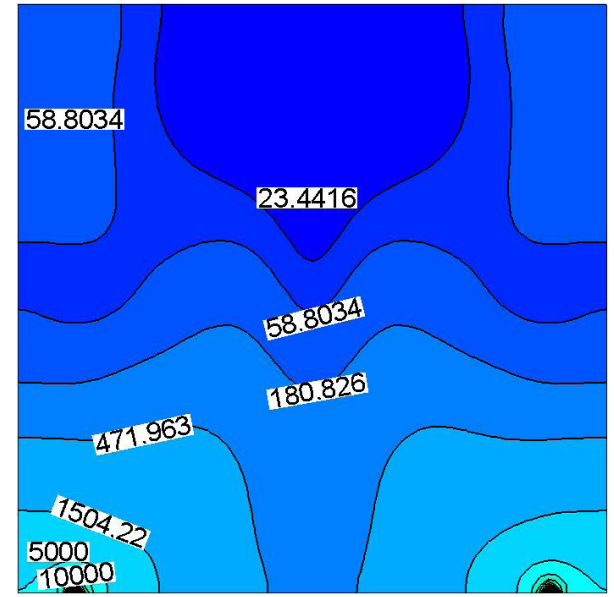

(a)

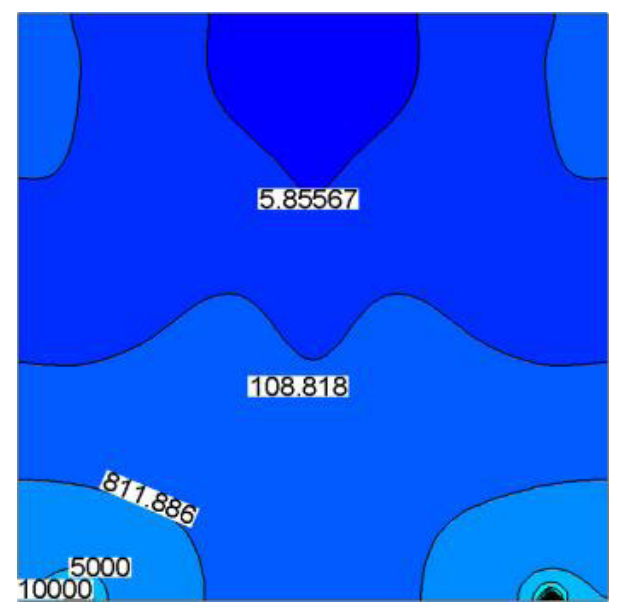

(b)

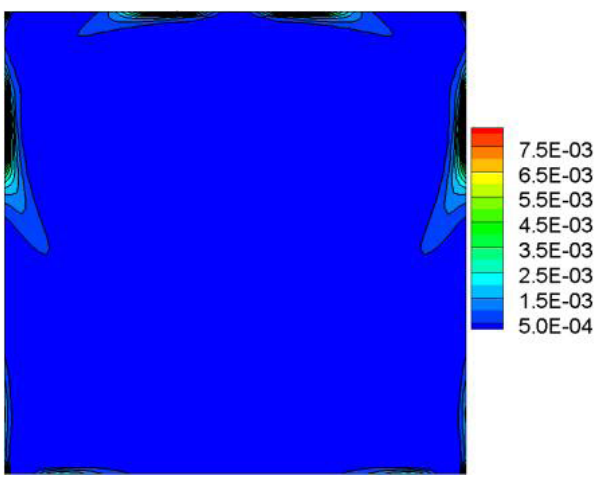

(c)

Fig. 13 (a) Contour of the total entropy generation $S_{g e n}$, (b) the entropy generation due to heat transfer $S_{t h}$, and (c) the entropy generation due to fluid friction $S_{f f}$ for mercury at $\mathrm{Ri}=85$

there are slight differences depending on the type of fluid and whether the flow structure is two or four cells (before or after the bifurcation). In the case where the flow is characterized by two cells, the entropy generation is maximum and more important at the lower-left (or right) wall than at

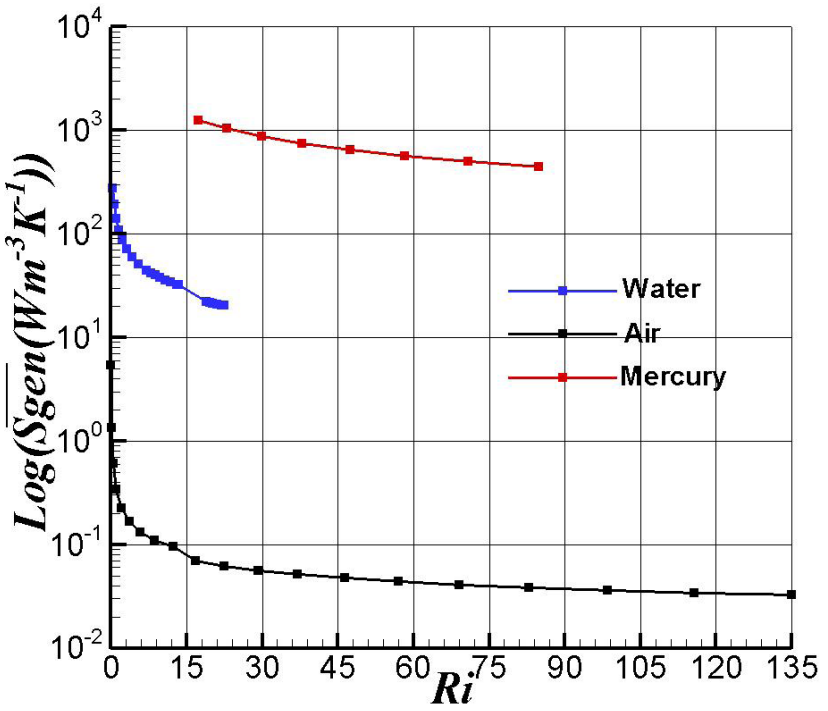

Fig. 14 Comparison of the average total entropy generation for the working fluids versus the Richardson number

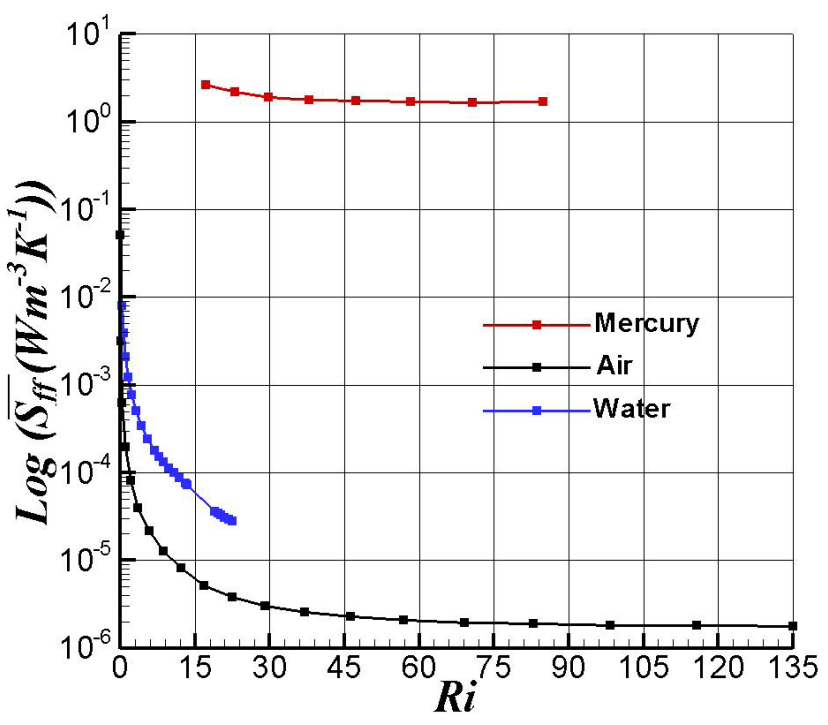

Fig. 15 Comparison of the average entropy generation due to fluid friction for the working fluids versus the Richardson number

the two ends of the heat source in the case of water compared to the air case. This can be explained by the fact that more heat is removed from the heat source in the case of water than in the case of air as shown in the left column of Figs. 2 and 3. Starting at the left (or right) end of the heat source a sudden drop of the entropy generation is observed and remains at an almost constant value throughout the heated section. In the situation where the flow is characterized by four cells, the entropy generation is maximal and more important at the two ends of the heat source on the left wall (or right) than at the lower-left (or right) wall. This is because in this case, all the heat is removed from the heat source through the center of the cavity, as shown 


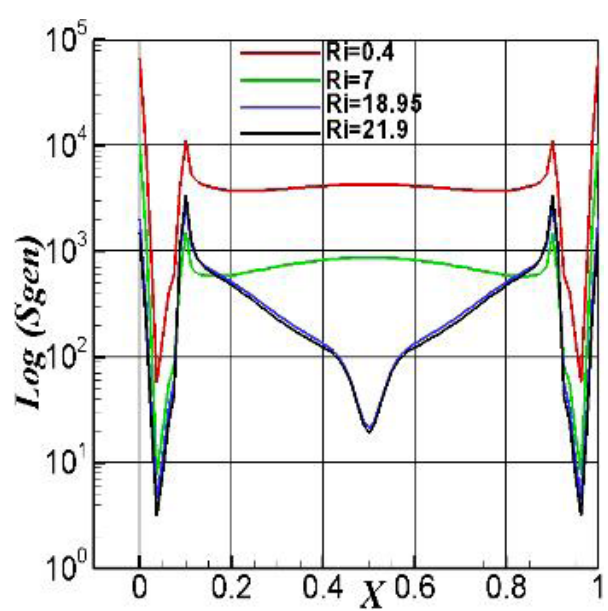

(a)

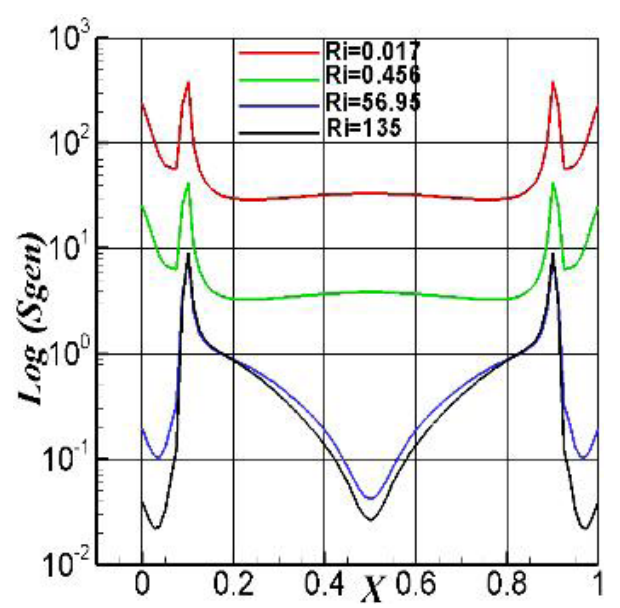

(b)

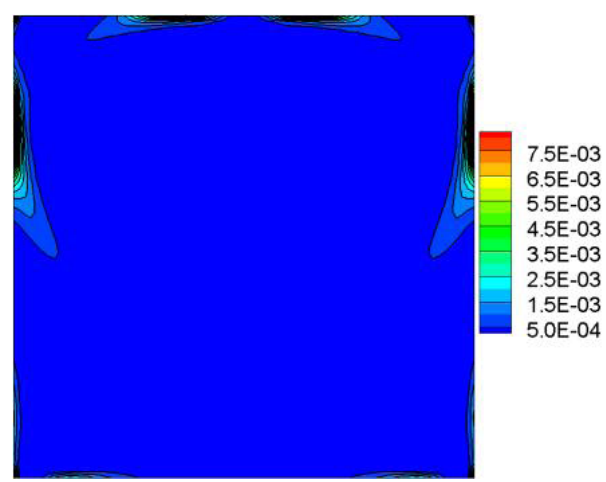

(c)

Fig. 16 Profiles of the entropy generation on the bottom wall at different values of Richardson numbers for (a) water, (b) air and (c) mercury

in the right column of Figs. 2 and 4. Entropy generation decreases sharply from the two ends of the heat source on the left wall (or right) and then continues to decrease gradually to reach its minimum value in the center of the cavity. This is because the vertical temperature gradient exhibits a minimum value in the middle of the heating element, as can be seen in Fig. 17. In addition, based the boundary conditions Eq. (8) and the fact that the entropy generation due to viscous effects is negligible the total entropy generation Eq. (12) is reduced to:

$$
\left.\overline{S_{g e n}}\right|_{Y=0} \approx S_{1}\left(\frac{\partial \theta}{\partial Y}\right)_{Y=0}^{2},
$$

which involve a minimum value of this one.

Nevertheless and contrary to the cases of water and air, mercury for which the flow is characterized only by four cells, the generation entropy decreases in a parabolic way from the two ends of the heat source on the left wall (or right) to the center of the cavity. In addition, it should be noted that when the natural convection dominates (larger values of the Richardson number), entropy generation becomes independent of the Richardson number meaning that the temperature gradients decrease significantly in the central region and that entropy generation tends towards a relatively constant limit.

\section{Conclusion}

A numerical study is carried out to investigate the mixed convection within a square cavity partially heated from below with moving cooled vertical sidewalls. This investigation focused on the effect of the Prandtl number on the entropy generation.

Based on the obtained results, we can conclude that:

1. The Prandtl number strongly affects the velocity and temperature fields and, therefore, also the entropy generation.

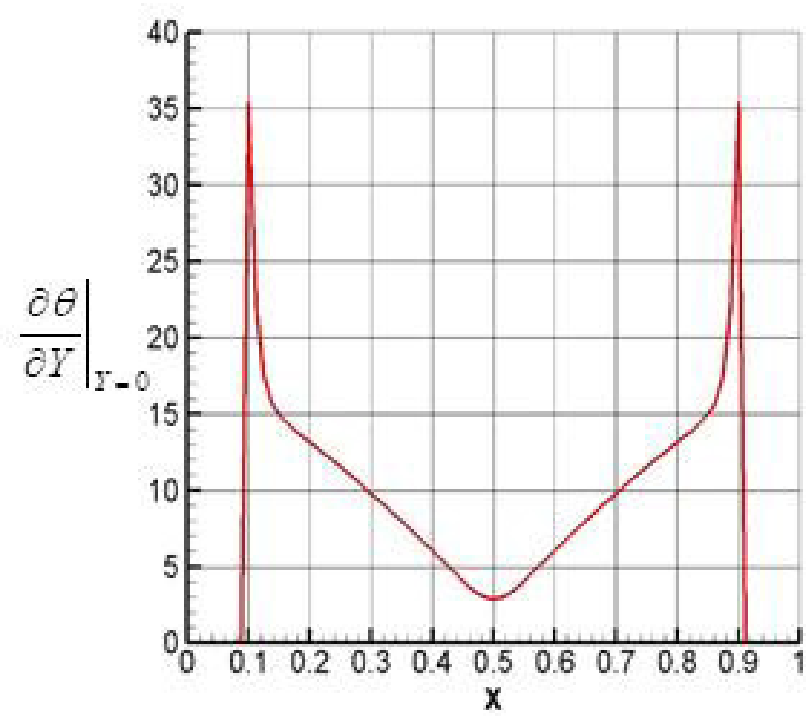

Fig. 17 Vertical temperature gradient on the bottom wall at $\mathrm{Ri}=56.96$ for air 
2. The irreversibilities are dominant due to heat transfer whereas fluid friction irreversibilities represent only a minor part of the total entropy generation. This is valid irrespective of the Prandtl and Richardson numbers.

3. The entropy is mainly generated at the bottom cavity wall. The peak values are observed at the lower-left (or right) corner $(x=0 ; x=1)$ and at both ends of the heat source $(x=0.1 ; x=0.9)$.

4. The average total entropy generation decreases by increasing the Richardson number and it is found to be high for mercury $(P r=0.0251)$ and water $(P r=6.263)$ compared to that of air $(P r=0.7296)$. Therefore, it is highly recommended, the use of this fluid in heat transfer processes.

\section{Acknowledgement}

The authors like to express their thankfulness to the Computational Fluid Dynamics Laboratory of the Mechanical Engineering Department, of Istanbul Medeniyet University for having provided computer facilities during this work.

\section{Nomenclature}

Be Bejan number

$g \quad$ Gravitational acceleration, $\mathrm{ms}^{-2}$

Gr Grashof number $\left(=g \beta \Delta T L^{3} / v^{2}\right)$

$k \quad$ Thermal conductivity, $\mathrm{Wm}^{-1} \mathrm{~K}^{-1}$

$l \quad$ Length of the heat source, $\mathrm{m}$

$L \quad$ Length of the square cavity, m

$\mathrm{Nu} \quad$ Nusselt number

$p \quad$ Fluid pressure, $\mathrm{Pa}$

$P \quad$ Dimensionless pressure

Pr Prandtl number, $(=v / \alpha)$

\section{References}

[1] Bejan, A. "Entropy Generation through Heat and Fluid Flow", John Wiley and Sons, New York, NY, USA, 1982.

[2] Bejan, A. "Advanced Engineering Thermodynamics", John Wiley and Sons, New York, NY, USA, 1988.

[3] Dincer, I., Cengel, Y. A. "Energy, Entropy and Exergy Concepts and Their Roles in Thermal Engineering", Entropy, 3(3), pp. 116-149, 2001.

https://doi.org/10.3390/e3030116

[4] Naterer, G. F., Camberos, J. A. "Entropy and the Second Law Fluid Flow and Heat Transfer Simulation", Journal of Thermophysics and Heat Transfer, 17(3), pp. 360-371, 2003.

https://doi.org/10.2514/2.6777
Ra Rayleigh number, (= Gr Pr)

Re Reynolds number, $\left(=v_{w} L / v\right)$

$\mathrm{Ri} \quad$ Richardson number ( $\left.=\mathrm{Ra} / \mathrm{PrRe}^{2}\right)$

$S_{g e n} \quad$ Entropy generation, $\mathrm{Wm}^{-3} \mathrm{~K}^{-1}$

$t \quad$ Time, $\mathrm{s}$

$T \quad$ Absolute temperature, $\mathrm{K}$

$T_{c} \quad$ Sidewall temperature, $\mathrm{K}$

$T_{h} \quad$ Heat source temperature, $\mathrm{K}$

$T_{r e f} \quad$ Bulk temperature $\left.\left(T_{h}+T_{c}\right) / 2\right), \mathrm{K}$

$u, v \quad$ Velocity components in $\mathrm{x}, \mathrm{y}$ directions, $\mathrm{m} \mathrm{s}^{-1}$

$U, V \quad$ Dimensionless velocities in $\mathrm{X}$ and $\mathrm{Y}$ direction

$v_{w} \quad$ Sidewall velocity, $\mathrm{m} \mathrm{s}^{-1}$

$x, y \quad$ Dimensional Cartesian coordinates, $\mathrm{m}$

$X, Y \quad$ Dimensionless Cartesian coordinates

\section{Greek symbols}

$\alpha \quad$ Thermal diffusivity, $\mathrm{m}^{2} \mathrm{~s}^{-1}$

$\beta \quad$ Thermal expansion coefficient, $\mathrm{K}^{-1}$

$\varepsilon \quad$ Dimensionless length of the heat source $(l / L)$

$\Delta T \quad$ Temperature difference $\left(T_{h}-T_{c}\right), \mathrm{K}$

$\theta$ Dimensionless temperature

$v \quad$ Kinematic viscosity, $\mathrm{m}^{2} \mathrm{~s}^{-1}$

$\mu \quad$ Dynamic viscosity, $\mathrm{kg} \mathrm{m}^{-1} \mathrm{~s}^{-1}$

$\rho \quad$ Density, $\mathrm{kg} \mathrm{m}^{-3}$

$\tau \quad$ Dimensionless time

$\psi \quad$ Stream function, $\mathrm{m}^{2} \mathrm{~s}^{-1}$

$\Psi \quad$ Dimensionless stream function

$\omega \quad$ Vorticity, $\mathrm{s}^{-1}$

$\Omega \quad$ Dimensionless vorticity

\section{Subscripts}

ff Fluid friction

th Heat transfer

[5] Sciacovelli, A., Verda, V., Sciubba, E. "Entropy generation analysis as a design tool - A review", Renewable and Sustainable Energy Reviews, 43, pp. 1167-1181, 2015. https://doi.org/10.1016/j.rser.2014.11.104

[6] Sauerheber, R. "Thermodynamics and Entropy in Natural and Artificial Systems", American Research Journal of Chemistry, 2(1), pp. 1-26, 2018. https://doi.org/10.21694/2577-5898.18001

[7] Bejan, A. "Second law analysis in heat transfer", Energy, 5(8-9), pp. 720-732, 1980 . https://doi.org/10.1016/0360-5442(80)90091-2

[8] Bejan, A. "Entropy Generation Minimization", CRC Press, Boca Raton, FL, USA, 1996. 
[9] Oztop, H. F., Al-Salem, K. "A review on entropy generation in natural and mixed convection heat transfer for energy systems", Renewable and Sustainable Energy Reviews, 16(1), pp. 911-920, 2012.

https://doi.org/10.1016/j.rser.2011.09.012

[10] Awad, M. M. "A review of entropy generation in micro channels", Advances in Mechanical Engineering, 7(12), pp. 1-32, 2015. https://doi.org/10.1177/1687814015590297

[11] Biswal, P., Basak, T. "Entropy generation vs energy efficiency for natural convection based energy flow in enclosures and various applications: A review", Renewable and Sustainable Energy Reviews, 80, pp. 1412-1457, 2017. https://doi.org/10.1016/j.rser.2017.04.070

[12] Torabi, M., Zhang, K., Karimi, N., Peterson, G. P. "Entropy generation in thermal systems with solid structures - A concise review", International Journal of Heat and Mass Transfer, 97, pp. 917-931, 2016.

https://doi.org/10.1016/j.ijheatmasstransfer.2016.03.007

[13] Cheng, T. S. "Characteristics of mixed convection heat transfer in a lid-driven square cavity with various Richardson and Prandtl numbers", International Journal of Thermal Sciences, 50(2), pp. 197-205, 2011.

https://doi.org/10.1016/j.ijthermalsci.2010.09.012

[14] Błasiak, P., Kolasiński, P. "Modelling of the mixed convection in a lid-driven cavity with a constant heat flux boundary condition", Heat and Mass Transfer, 52(3), pp. 595-609, 2016. https://doi.org/10.1007/s00231-015-1583-6

[15] Rahman, M.s., Nasrin, R., Hoque, M. I. "Prandtl Number Effect on Nanofluid Flow inside a Porous Cavity", In: The IIER International Conference, Dhaka, Bangladesh, 2018, pp. 1-6

[16] Moon, J. Y., Chung, B. J. "Influence of Prandtl number, height and lateral cooling condition on laminar natural convection in a rectangular enclosure", Heat and Mass Transfer, 55(6), pp. 1593-1605, 2019.

https://doi.org/10.1007/s00231-018-02540-7

[17] Kaluri, R. S., Basak, T. "Entropy generation due to natural convection in discretely heated porous square cavities", Energy, 36(8), pp. 5065-5080, 2011.

https://doi.org/10.1016/j.energy.2011.06.001

[18] Ramakrishna, D., Basak, T., Roy, S., Momoniat, E. "Analysis of thermal efficiency via analysis of heat flow and entropy generation during natural convection within porous trapezoidal cavities", International Journal of Heat and Mass Transfer, 77, pp. 98-113, 2014.

https://doi.org/10.1016/j.ijheatmasstransfer.2014.04.002

[19] Rathnam, V. M., Roy, M., Basak, T. "Analysis of entropy generation during natural convection in tilted triangular enclosures with various base angles", Numerical Heat Transfer; Part A: Applications, 69(12), pp. 1332-1354, 2016. https://doi.org/10.1080/10407782.2016.1139976

[20] Wei, Y., Wang, Z., Qian, Y. "A Numerical Study on Entropy Generation in Two-Dimensional Rayleigh-Bénard Convection at Different Prandtl Number", Entropy, 19(9), Article number: 443, 2017.

https://doi.org/10.3390/e19090443
[21] Pordanjani, A. H., Aghakhani, S., Karimipour, A., Afrand, M., Goodarzi, M. "Investigation of free convection heat transfer and entropy generation of nanofluid flow inside a cavity affected by magnetic field and thermal radiation", Journal of Thermal Analysis and Calorimetry, 137(3), pp. 997-1019, 2019. https://doi.org/10.1007/s10973-018-7982-4

[22] Mliki, B., Abbassi, M. A. "Entropy generation of MHD natural convection heat transfer in a heated incinerator using hybrid-nanoliquid", Propulsion and Power Research, 2021. https://doi.org/10.1016/j.jppr.2021.01.002

[23] Roy, M., Roy, S., Basak, T. "Analysis of entropy generation on mixed convection in square enclosures for various horizontal or vertical moving wall(s)", International Communications in Heat and Mass Transfer, 68, pp. 258-266, 2015.

https://doi.org/10.1016/j.icheatmasstransfer.2015.08.023

[24] Roy, M., Basak, T., Roy, S. "Analysis of Entropy Generation During Mixed Convection in Porous Square Cavities: Effect of Thermal Boundary Conditions", Numerical Heat Transfer; Part A: Applications, 68(9), pp. 925-957, 2015. https://oi.org/10.1080/10407782.2015.1023134

[25] Roy, M., Basak, T., Roy, S., Pop, I. "Analysis of Entropy Generation for Mixed Convection in a Square Cavity for Various Thermal Boundary Conditions", Numerical Heat Transfer; Part A: Applications, 68(1), pp. 44-74, 2015. https://doi.org/10.1080/10407782.2014.955352

[26] Roy, M., Biswal, P., Roy, S., Basak, T. "Role of various moving walls on entropy generation during mixed convection within entrapped porous triangular cavities", Numerical Heat Transfer; Part A: Applications, 71(4), pp. 423-447, 2017. https://doi.org/10.1080/10407782.2016.1277927

[27] Goodarzi, M., Safaei, M. R., Oztop, H. F., Karimipour, A., Sadeghinezhad, E., Dahari, M., Kazi, S. N., Jomhari, N. "Numerical Study of Entropy Generation Due to Coupled Laminar and Turbulent Mixed Convection and Thermal Radiation in an Enclosure Filled with a Semitransparent Medium", The Scientific World Journal, 2014, Article ID: 761745, 2014.

https://doi.org/10.1155/2014/761745

[28] Aghaei, A., Sheikhzadeh, G. A., Goodarzi, M., Hasani, H., Damirchi, H., Afrand, M. "Effect of horizontal and vertical elliptic baffles inside an enclosure on the mixed convection of a MWCNTs-water nanofluid and its entropy generation", European Physical Journal Plus, 133(11), Article number: 486, 2018.

https://doi.org/10.1140/epjp/i2018-12278-4

[29] Yousefzadeh, S., Rajabi, H., Ghajari, N., Sarafraz, M. M., Akbari, O. A., Goodarzi, M. "Numerical investigation of mixed convection heat transfer behavior of nanofluid in a cavity with different heat transfer areas", Journal of Thermal Analysis and Calorimetry, 140(6), pp. 2779-2803, 2020.

https://doi.org/10.1007/s10973-019-09018-6

[30] Ebrahimi, D., Yousefzadeh, S., Akbari, O. A., Montazerifar, F., Rozati, S. A., Nakhjavani, S., Safaei, M. R. "Mixed convection heat transfer of a nanofluid in a closed elbow-shaped cavity (CESC)", Journal of Thermal Analysis and Calorimetry, 144(6), pp. 2295-2316, 2021.

https://doi.org/10.1007/s10973-021-10548-1 
[31] Kashyap, D., Dass, A. K., Oztop, H. F., Abu-Hamdeh, N. "Multiplerelaxation-time lattice Boltzmann analysis of entropy generation in a hot-block-inserted square cavity for different Prandtl numbers", International Journal of Thermal Sciences, 165, Article number: 106948, 2021.

https://doi.org/10.1016/j.ijthermalsci.2021.106948

[32] Khan, U., Zaib, A., Khan, I., Nisar, K. S. "Entropy Generation Incorporating $\gamma$-Nanofluids under the Influence of Nonlinear Radiation with Mixed Convection", Crystals, 11(4), Article number: 400, 2021.

[33] Gray, D. D., Giorgini, A. "The validity of the boussinesq approximation for liquids and gasses", International Journal of Heat and Mass Transfer, 19(5), pp. 545-551, 1976.

https://doi.org/10.1016/0017-9310(76)90168-X

[34] Jayanthi, S., Kavitha, T. "A modified compact numerical algorithm to solve 2D Navier-Stokes equation", Results in Applied Mathematics, 3, Article number: 100065, 2019.

https://doi.org/10.1016/j.rinam.2019.100065

[35] Abbasian Arani, A. A., Monfaredi, F., Aghaei, A., Afrand, M., Chamkha, A. J., Emami, H. "Thermal radiation effect on the flow field and heat transfer of $\mathrm{Co}_{3} \mathrm{O}_{4}$-diamond/EG hybrid nanofluid using experimental data: A numerical study", European Physical Journal Plus, 134(1), Article number: 13, 2019.

https://doi.org/10.1140/epjp/i2019-12431-7

[36] Kawamura, T., Takami, H., Kuwahara, K. "New higher-order upwind scheme for incompressible Navier-Stokes equations", In: Soubbaramayer, Boujot, J. P. (eds.) Ninth International Conference on Numerical Methods in Fluid Dynamics, Springer, Berlin, Heidelberg, Germany, 1985, pp. 291-295. https://doi.org/10.1007/3-540-13917-6_152

[37] De Vahl Davis, G., Jones, I. P. "Natural convection in a square cavity: A comparison exercise", International Journal for Numerical Methods in Fluids, 3(3), pp. 227-248, 1983. https://doi.org/10.1002/fld.1650030304

[38] De Vahl Davis, G. "Natural convection of air in a square cavity: A bench mark numerical solution", International Journal for Numerical Methods in Fluids, 3(3), pp. 249-264, 1983. https://doi.org/10.1002/fld.1650030305
[39] Balam, N. B., Gupta, A. "Numerical solution of natural-convection flow in enclosures: An implicit vorticity boundary condition type method", Heat Transfer Research, 50(14), pp. 1383-1416, 2019. https://doi.org/10.1615/heattransres.2019028547

[40] Ilis, G. G., Mobedi, M., Sunden, B. "Effect of aspect ratio on entropy generation in a rectangular cavity with differentially heated vertical walls", International Communications in Heat and Mass Transfer, 35(6), pp. 696-703, 2008. https://doi.org/10.1016/j.icheatmasstransfer.2008.02.002

[41] Oliveski, R. D. C., Macagnan, M. H., Copetti, J. B. "Entropy generation and natural convection in rectangular cavities", Applied Thermal Engineering, 29(8-9), pp. 1417-1425, 2009. https://doi.org/10.1016/j.applthermaleng.2008.07.012

[42] Shavik, S. M., Nasim Hassan, M., Monjur Morshed, A. K. M., Quamrul Islam, M. "Natural Convection and Entropy Generation in a Square Inclined Cavity with Differentially Heated Vertical Walls", Procedia Engineering, 90, pp. 557-562, 2014. https://doi.org/10.1016/j.proeng.2014.11.772

[43] Jassim, H. M., Ali, F. H., Al-Amir, Q. R., Hamzah, H. K., Khafaji, S. O. W. "Entropy generation analysis of a natural convection inside a sinusoidal enclosure with different shapes of cylinders", Frontiers in Heat and Mass Transfer, 12, Article number: 22, 2019. https://doi.org/10.5098/hmt.12.22

[44] Çengel, Y. A., Ghajar, A. J. "Heat and Mass Transfer: Fundamentals \& Applications", McGraw Hill Education, London, UK, 2015.

[45] Biswas, N., Manna, N. K. "Transport phenomena in a sidewall-moving bottom-heated cavity using heat lines", Sādhanā, 42(2), pp. 193-211, 2017. https://doi.org/10.1007/s12046-016-0586-4

[46] Moallemi, M. K., Jang, K. S. "Prandtl number effects on laminar mixed convection heat transfer in a lid-driven cavity", International Journal of Heat and Mass Transfer, 35(8), pp. 1881-1892, 1992. https://doi.org/10.1016/0017-9310(92)90191-T

[47] Monaledi, R. L, Makinde, O. D. "Entropy generation analysis in a microchannel Poiseuille flows of nanofluid with nanoparticles injection and variable properties", Journal of Thermal Analysis and Calorimetry, 143(3), pp. 1855-1865, 2021. https://doi.org/10.1007/s10973-020-09919-x 